\title{
Experimental Assessment of Premixed Flames Subjected to Extreme Turbulence
}

\author{
Aaron W. Skiba ${ }^{1}$, Timothy M. Wabel ${ }^{2}$, Jacob E. Temme ${ }^{3}$, and James F. Driscoll ${ }^{4}$ \\ Department of Aerospace Engineering \\ University of Michigan, Ann Arbor MI 48109
}

\begin{abstract}
Structural features of highly turbulent piloted flames were acquired from simultaneous PLIF images of formaldehyde $\left(\mathrm{CH}_{2} \mathrm{O}\right)$ and $\mathrm{OH}$. Both lean and near-stoichiometric (equivalence ratio $\phi=0.75$ and 1.05, respectively) methane-air flames were studied under twelve different flow conditions and at two different interrogation regions. The non-reacting conditions for these flames consist of turbulent Reynolds numbers $\left(\operatorname{Re}_{T}\right)$, turbulence intensities $\left(u^{\prime} / S_{L}\right)$, and integral length scales that range from 520 to 80,000; 5 to 185; and 6 $\mathrm{mm}$ to $37 \mathrm{~mm}$, respectively. Eight of the twelve cases have $u^{\prime} / \mathrm{S}_{L}>25$ and thus are classified into a regime of extreme turbulence. Preheat and reaction zone thicknesses were measured in all twelve cases. The preheat zone thickness was interpreted from the $\mathrm{CH}_{2} \mathrm{O}$ PLIF images and the reaction zone thicknesses were obtained from the profiles derived from the pixel-by-pixel product of the $\mathrm{OH}$ and $\mathrm{CH}_{2} \mathrm{O}$ PLIF images. The preheat zones associated with a particular condition were classified as being "thickened" if the mean thickness for that condition exceeded two but not four times the measured laminar value $(0.42$ and $0.39 \mathrm{~mm}$ for lean and rich flames, respectively). If the average thickness was greater than four times the measured laminar value that preheat zone was deemed "primarily distributed." Ten of the twelve cases possessed "primarily distributed" preheat zones, while those in the two least turbulent cases were "thickened." The majority of the cases possessed average reaction layer thicknesses that are no thicker than twice the measured laminar value (0.39 and $0.38 \mathrm{~mm}$ for lean and rich flames, respectively); hence, they were identified as having "thin" reaction layers. Regardless of being categorized as "thin," the reaction zones in each case exhibited regions of both relatively thin and thick reaction layers. In fact the appearance of the observed reaction zones can best be described as resembling "chicken noodle soup." That is, in any given instantaneous image relatively thin, "noodle-like" reaction layers are generally accompanied by thicker "chunky-chicken-like" reaction regions. Furthermore, the observed reaction zone structures in a particular case often fail to correspond to those predicted by the turbulent premixed combustion regime diagram. This suggests that the regime diagram requires alterations if it is to properly forecast the appearance of a flame based on a simple set of operating conditions. The data set presented here is currently too limited to enable a thorough re-mapping of the regime diagram. However, based on their structural features, the cases considered here were categorized into appropriate regimes of combustion.
\end{abstract}

\section{Introduction}

Premixed flames are advantageous because they typically generate less emissions (e.g. $\mathrm{NO}_{\mathrm{x}}$ ) than nonpremixed flames. Given today's stringent emission policies, it is not surprising that modern power-production and propulsion systems have begun to implement premixed combustion strategies. To enhance mixing and hence, to allow devices to be more compact, modern power-production and propulsion devices generally operate under highly turbulent conditions. Yet, the presence of highly turbulent flows within such devices renders their design and development quite challenging. Practical and economical design of these devices necessitates the implementation of computational models. The accuracy of turbulent premixed combustion models rests on their ability to properly simulate the underlying physics inherent to such combustion. However, the fundamental physics of premixed

\footnotetext{
${ }^{1}$ Research Assistant, Department of Aerospace Engineering, AIAA Member.

${ }^{2}$ Research Assistant, Department of Aerospace Engineering, AIAA Member.

3 Post-Doctoral Researcher, U.S. Army Research Laboratory, Aberdeen Proving Ground, MD 21005 USA.

${ }^{4}$ Professor, Department of Aerospace Engineering, AIAA Fellow.
} 
combustion occurring within the highly turbulent flows of modern, low-emission devices is currently unresolved. Thus, this work aims to extend the combustion community's understanding of premixed flames to regimes of turbulence that are much more instance than those in previous studies.

Numerous studies ${ }^{1-18}$ of turbulent premixed flames have been conducted with relatively large turbulence intensities (i.e. $\mathrm{u}^{\prime} / \mathrm{S}_{\mathrm{L}}$, where $\mathrm{u}^{\prime}$ is square root of the velocity's variance and $\mathrm{S}_{\mathrm{L}}$ is the un-stretched laminar flame speed) but with rather small integral length scales (typically on the order of several millimeters). Yet, modern combustion devices generally operate with both large turbulence intensities and integral length scales. That is, in realistic devices, combustion occurs within flows where both u' and $\lambda$ are large; or, in other words, when the turbulence Reynolds number $\left(\operatorname{Re}_{\mathrm{T}}\right)$ is large. Where,

$$
\operatorname{Re}_{\mathrm{T}}=\frac{\mathrm{u}^{\prime} \lambda}{v}
$$

and $v$ is the kinematic viscosity.

Besides $\mathrm{Re}_{\mathrm{T}}$, the turbulent Damköhler (DaT) and turbulent Karlovitz (Ka ${ }_{\mathrm{T}}$ numbers are two additional dimensionless parameters used to characterize turbulent premixed combustion. The Damköhler number represents the ratio of time scales associated with large flow structures to those of a flame's chemical reactions. In contrast, the Karlovitz number signifies the ratio of a flame's chemistry time scale to those of the smallest structures in a turbulent flow. The turbulent Damköhler and turbulent Karlovitz numbers are defined as:

$$
\begin{gathered}
\mathrm{Da}_{\mathrm{T}}=\frac{\mathrm{S}_{\mathrm{L}}^{2} \lambda}{\mathrm{u}^{\prime} v} \\
\mathrm{Ka}_{\mathrm{T}}=\frac{\delta_{\mathrm{F}, \mathrm{L}} u^{\prime 3}}{\mathrm{~S}_{\mathrm{L}}^{3} \lambda}
\end{gathered}
$$

where $\delta_{\mathrm{F}, \mathrm{L}}$ is the un-stretched laminar flame thickness.

As $\mathrm{Ka}_{\mathrm{T}}$ increases and $\mathrm{Da}_{\mathrm{T}}$ decreases the characteristic time scales of turbulence become comparable to those of a flame's chemical reactions. In fact, it is theorized that once $\mathrm{Da}_{\mathrm{T}}$ drops below or Kaт rises above a critical value, the smallest scales of a turbulent flow not only penetrate a flame but contain enough energy to dramatically distort its spatial structure ${ }^{19,20}$. In fact, Williams ${ }^{19}$ suggests that a flame's chemical reactions become distributed (i.e. significantly smeared over a large spatial region) for conditions in which $\mathrm{Da}_{\mathrm{T}}<1$. In contrast, Peters ${ }^{20}$ postulates that premixed flames become broken when $\mathrm{Ka}_{\mathrm{T}}>100$. Yet, based on direct numerical simulations (DNSs), Aspden et al. ${ }^{21}$ insisted that both broken and distributed reactions may be present when Ka $\mathrm{T}_{\mathrm{T}}$ is sufficiently large. Furthermore, Zhou et al. ${ }^{18}$ point out that whether a flame exhibits broken or distributed reactions may rest on how well it is shielded by a hot co-flow.

Prior to the work presented here, few experimental studies have been conducted in which turbulence levels were high enough to produce distributed or broken reaction zones. For instance, prior to 2009 flame structure imaging experiments typically operated with $\mathrm{Re}_{\mathrm{T}}$ values no greater than $2,000^{1-11}$. Nearly all of the reaction layers in these studies were rather thin and continuous. However, significant flame extinction was observed by Mansour et al. ${ }^{12}$, Chen et al. ${ }^{13}$, and Chen and Mouser ${ }^{14}$ in highly strained Bunsen flames that were surrounded by a large diameter pilot. Similar flames surrounded by a hot co-flow were investigated by Dunn et al. ${ }^{15,16}$, who observed localized flame extinction when $\operatorname{Re}_{\mathrm{T}}$ was 3,700 and 5,500.

More recently, Zhao et al. ${ }^{17,18}$ imaged flame structures in jet flames surrounded by a relatively large porousplug pilot, where $\operatorname{Re}_{\mathrm{T}}$ was approximately 5,000. Though they did not report evidence of significant local flame extinction, planar laser induced florescence (PLIF) images of $\mathrm{CH}$ and $\mathrm{HCO}$ radicals did suggest the presence of distributed reactions. Regions of distributed combustion were also observed by Aspden et al. ${ }^{21}$. In their DNS studies of three-dimensional Hydrogen flames in a box, distributed reaction zones were found to exists when $\mathrm{Da}_{\mathrm{T}}=1.52 \times 10^{-}$ ${ }^{2}$ and $\mathrm{Ka}_{\mathrm{T}}=266$. This demonstrates that in addition to having large values of $\mathrm{Re}_{\mathrm{T}}$, having large $\mathrm{Ka}_{\mathrm{T}}$ and low $\mathrm{Da}_{\mathrm{T}}$ values may be required in order for flames to possess distributed reactions. 
The "distributed reaction" regime is one of several to appear on the turbulent premixed combustion regime diagram. There are currently two ways of plotting the turbulent premixed combustion regime diagram. The first is the regime diagram as proposed by $\mathrm{F}$. Williams ${ }^{19}$, which plots $\mathrm{Da}_{\mathrm{T}}$ as a function of $\mathrm{Re}_{\mathrm{T}}$ on a $\log$ - $\log$ scale. The second is the diagram proposed by Peters ${ }^{20}$ and Borghi ${ }^{22}$, which adopts $\mathrm{u}^{\prime} / \mathrm{S}_{\mathrm{L}}$ and $\lambda / \delta_{\mathrm{F}, \mathrm{L}}$ as the governing parameters. The authors believe that both methods of plotting the regime diagram are adequate and that neither one is particularly better than the other. However, for brevities sake, this document only presents the diagram proposed by Borghi and Peters. This "Borghi Diagram" is provided in Figure 1.

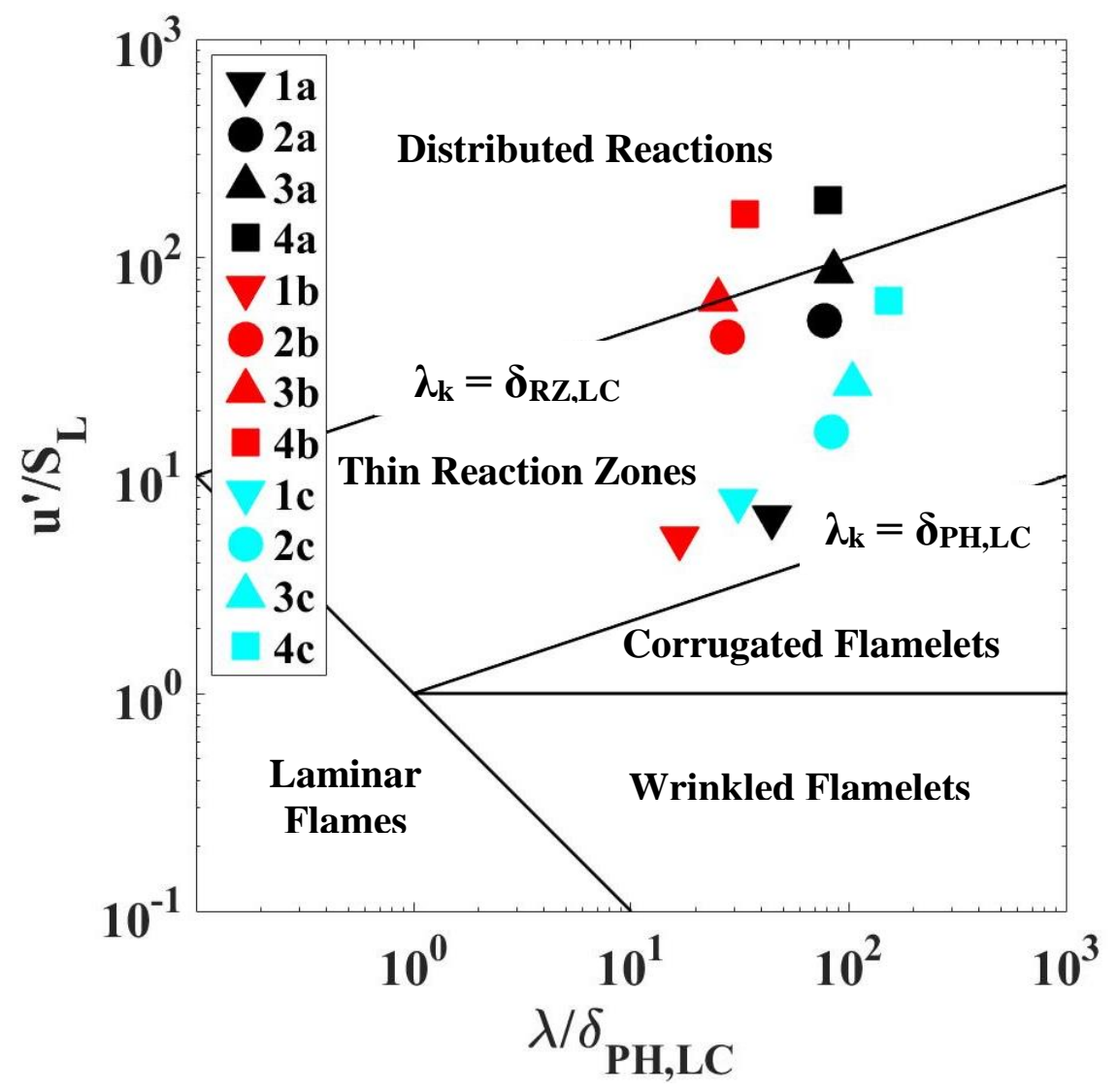

Figure 1. The turbulent premixed combustion regime diagram proposed by Borghi ${ }^{22}$, and Peters ${ }^{20}$, which has a modified $\mathrm{X}$-axis and includes the cases considered in this paper. Nomenclature: $\delta_{\mathrm{RZ}, \mathrm{LC}}$ and $\delta_{\mathrm{PH}, \mathrm{LC}}$ the un-stretched laminar reaction and preheat zone thickness computed by CHEMKIN (see section II.B below), respectively, and $\lambda_{\mathrm{k}}$ is the Kolmogorov length scale.

Notice that the "Borghi Diagram" in Figure 1 contains two modifications: the present experimental test cases have been included and the $\mathrm{x}$-axis is normalized by the un-stretched laminar preheat zone thickness, $\delta_{\mathrm{PH}, \mathrm{LC}}$ instead of $\delta_{\mathrm{F}, \mathrm{L}}$. To remain consistent with this modification, $\delta_{\mathrm{F}, \mathrm{L}}$ in the definition of $\mathrm{Ka}_{\mathrm{T}}$, is also replaced by $\delta_{\mathrm{PH}, \mathrm{LC}}$; thus:

$$
\mathrm{Ka}_{\mathrm{T}}=\frac{\delta_{\mathrm{PH}, \mathrm{LC}} \mathrm{u}^{\prime 3}}{\mathrm{~s}_{\mathrm{L}}^{3} \lambda}
$$

The definition of $\delta_{\mathrm{PH}, \mathrm{L}}$ stems from the fact that the thickness of the total thermal front of an un-stretched laminar flame is the sum of the preheat and reaction zones; namely: 


$$
\delta_{\mathrm{F}, \mathrm{L}}=\delta_{\mathrm{PH}, \mathrm{L}}+\delta_{\mathrm{RZ}, \mathrm{L}}
$$

Where $\delta_{\mathrm{RZ}, \mathrm{L}}$ is the un-stretched laminar reaction zone thickness. Thus $\delta_{\mathrm{PH}, \mathrm{L}}$ is the difference between $\delta_{\mathrm{F}, \mathrm{L}}$ and $\delta_{\mathrm{RZ}, \mathrm{L}}$. Similarly, the turbulent flame thickness is defined as:

$$
\delta_{\mathrm{F}, \mathrm{T}}=\delta_{\mathrm{PH}, \mathrm{T}}+\delta_{\mathrm{RZ}, \mathrm{T}}
$$

Measuring the quantities in Eq. (8) is one of the objectives of this work.

\section{Experimental configuration}

This section outlies the experimental setup and the diagnostics used to conduct the work presented in this paper.

\section{A. Burner design}

This study investigated 12 separate premixed, methane-air flames that possessed a range of turbulence levels. Eight of these flames were lean (equivalence ratio $\phi=0.75$ ), while four were rich $(\phi=1.05$ ). All of the flames were produced by the Hi-Pilot Burner (HPB); however, the lean flames were stabilized by a much smaller pilot than the rich flames. A schematic of the HPB with both pilot-flame configurations and an image of each in operation are shown in Figure 2.
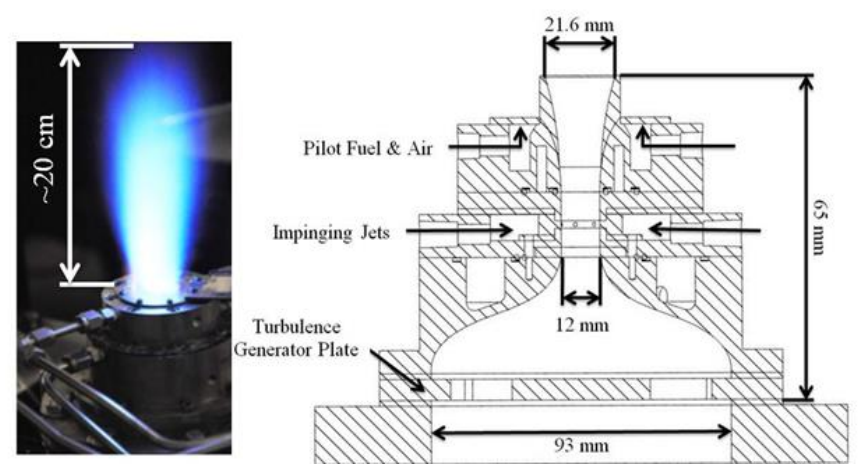

(a)
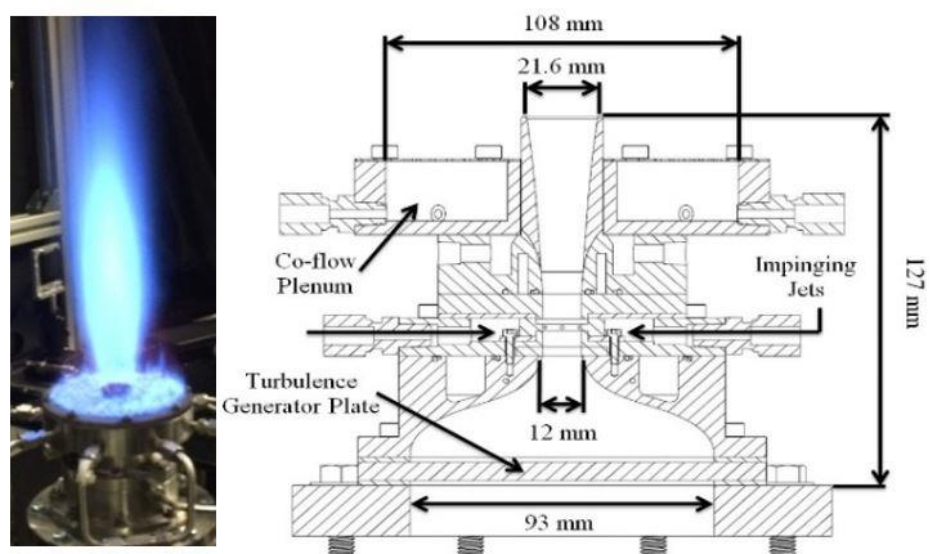

(b)

Figure 2. A schematic of the Hi-Pilot Burner and an associated flame image with and without the large diameter pilot in (a) and (b), respectively. 
The HPB is designed to provide extreme turbulence levels $\left(\mathrm{u}^{\prime} / \mathrm{S}_{\mathrm{L}}>25\right)$ and integral scales $(\lambda)$ that are nearly uniform in space, which avoids ambiguities as to where conditions lie on the regime diagram. This is achieved by expanding the flow at the jet exit, producing a relatively constant downstream turbulence level. An additional benefit of expanding the flow at the jet exit is the prevention of flame flashback, since the diverging walls produce gas velocities that increase in the upstream direction.

The HPB utilizes a slotted-contraction device, similar to that of Marshall et al. ${ }^{23}$ and Videto and Santavicca ${ }^{24}$, to generate extreme turbulence levels $\left(u^{\prime} / S_{L} \geq 25\right)$. Premixed reactants impinge on a slotted plate placed upstream of a converging-diverging section; this plate is labeled as the Turbulence Generator Plate in Figure 2. Two separate plates were utilized in these efforts; a diagram of these plates is provided in Figure 3.

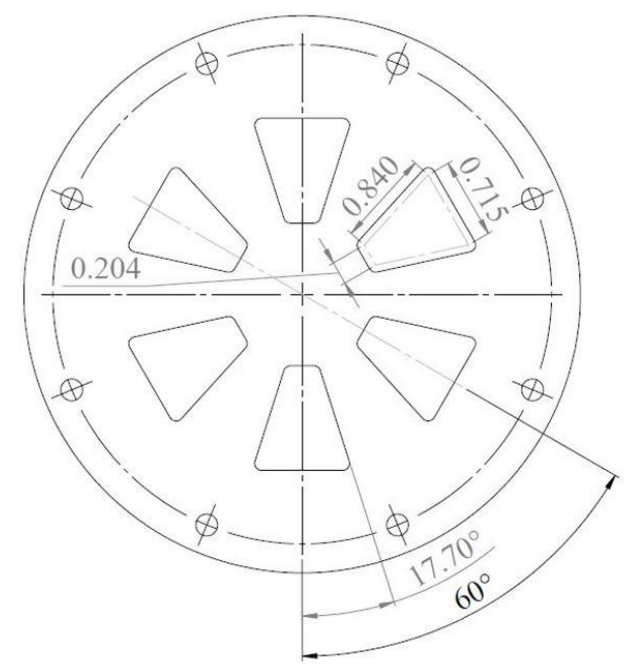

(a)

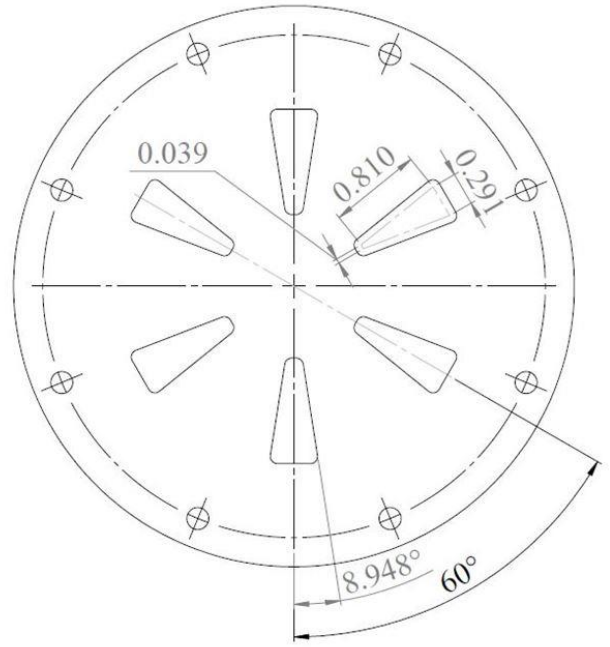

(b)

Figure 3. Slotted turbulence generating plates for the HPB. Note that the dimensions are given in inches.

The plates depicted in Figure 3a and 3b (hereinafter, "Plate a" and "Plate b," respectively) have blockage ratios of $70 \%$ and $80 \%$, respectively. Furthermore, the larger slots of Plate 'a' typically produced larger values of u' and $\lambda$ than Plate ' $b$ '. These separate plates allowed the HPB to generate two different flow conditions for a single flow rate. A total of eight distinct operating conditions (generated by the two slotted plates and four different flow rates) were studied with the small-pilot-flame configuration. While only four operating conditions (produced by combining the same four flow rates with Plate a) were investigated with the large-pilot-flame configuration. This resulted in a total of twelve distinct test cases in this experiment. The test cases utilizing the small-pilot-flame were labeled $1 \mathrm{a}-4 \mathrm{a}$ and $1 \mathrm{~b}-4 \mathrm{~b}$, with the increasing numbers representing increasing mass flow rate, and the letters representing either slotted Plate ' $a$ ' or ' $b$ '. Tests conducted with the large-pilot-flame were only operated with the lager slotted Plate 'a' and are labeled cases $1 \mathrm{c}-4 \mathrm{c}$.

The vortical structures that shed from these plates elongate through the HPB's contraction section, which lead to very large turbulence intensities. The amount of turbulence is enhanced by the addition of impinging jets, which are operated with the same equivalence ratio as the reactants and are injected perpendicular to the main flow at the throat of the converging-diverging section. This has the effect of breaking up the large eddies shed by the slotted plates and adds turbulent energy to the flow. The impinging jets are operated at $6 \%$ of the main flow rate. Operating conditions for the HPB are listed in Table 1 below. Note that cases 1a, 1b, and 1c were operated without impinging jets (to reduce the turbulence). 


\begin{tabular}{ccccccccccc}
\hline Case & $\phi$ & Pilot & $\mathrm{U}_{0}(\mathrm{~m} / \mathrm{s})$ & $\mathrm{u}^{\prime}(\mathrm{m} / \mathrm{s})$ & $\lambda(\mathrm{mm})$ & $\mathrm{Re}_{\mathrm{T}}$ & $\mathrm{Da}_{\mathrm{T}}$ & $\mathrm{Ka}_{\mathrm{T}}$ & $\mathrm{u}^{\prime} / \mathrm{S}_{\mathrm{L}}$ & $\lambda / \delta_{\mathrm{PH}, \mathrm{L}}$ \\
\hline 1a & 0.75 & Small & 6.2 & 1.5 & 16 & 1,600 & 38 & 2.5 & 6.5 & 39 \\
2a & 0.75 & Small & 40 & 12 & 28 & 22,000 & 8.2 & 42 & 52 & 66 \\
3a & 0.75 & Small & 55 & 20 & 31 & 40,000 & 5.4 & 86 & 86 & 73 \\
4a & 0.75 & Small & 110 & 43 & 29 & 80,000 & 2.4 & 281 & 185 & 68 \\
\hline 1b & 0.75 & Small & 5.1 & 1.2 & 6 & 520 & 18 & 2.9 & 5.2 & 15 \\
2b & 0.75 & Small & 30 & 10 & 10 & 6,400 & 3.5 & 54 & 43 & 24 \\
3b & 0.75 & Small & 37 & 15 & 9 & 8,700 & 2.1 & 104 & 65 & 21 \\
4b & 0.75 & Small & 79 & 37 & 12 & 29,000 & 1.1 & 349 & 160 & 28 \\
\hline 1c & 1.05 & Large & 14 & 2.9 & 7.5 & 1,400 & 24 & 3.8 & 7.7 & 19 \\
2c & 1.05 & Large & 32 & 6.0 & 20 & 7,900 & 31 & 7.0 & 16 & 51 \\
3c & 1.05 & Large & 44 & 10 & 25 & 17,000 & 23 & 13.4 & 27 & 63 \\
4c & 1.05 & Large & 64 & 24 & 37 & 58,000 & 14 & 41 & 64 & 95 \\
\hline
\end{tabular}

Table 1. Operating conditions for methane - air combustion with reactant temperature $\left(\mathrm{T}_{1}\right)$ and pressure $\left(\mathrm{P}_{1}\right)$ of 300 $\mathrm{K}$ and $1 \mathrm{~atm}$, respectively. Nomenclature: $\mathrm{U}_{0}$ is the centerline velocity measured approximately $5 \mathrm{~mm}$ above the burner, while u', $\lambda, \operatorname{Re}_{\mathrm{T}}, \mathrm{Da}_{\mathrm{T}}, \mathrm{Ka}_{\mathrm{T}}$, and $\mathrm{S}_{\mathrm{L}}$ are all defined in the text. Laminar flame measurements (discussed in section III.B below) gave $\delta_{\mathrm{PH}, \mathrm{L}}=0.42$ and $0.39 \mathrm{~mm}$ for the lean and rich flames, respectively. Additionally, a CHEMKIN simulation of a freely propagating flame with these specifications and employing GRI-Mech 3.0 gave $\mathrm{S}_{\mathrm{L}}$ $=23.2 \mathrm{~cm} / \mathrm{s}$ for cases $1 \mathrm{a}-4 \mathrm{a}$ and $1 \mathrm{~b}-4 \mathrm{~b}$ and $\mathrm{S}_{\mathrm{L}}=37.7 \mathrm{~cm} / \mathrm{s}$ for cases $1 \mathrm{c}-4 \mathrm{c}$.

\section{B. Diagnostics}

The flow field was characterized using a Laser Doppler Velocimeter (LDV) system. An Argon-Ion laser operating at 1.5 Watts (Coherent Innova 90c) and a commercial Doppler burst correlator (TSI FSA 4000) were used to measure the axial component of the jet centerline velocity. The tracer species used in this experiment was $0.5 \mu \mathrm{m}$ alumina-oxide particles, while the optical components and photomultiplier tube consisted of standard commercial LDV equipment (TSI). The LDV focal volume was approximately $5 \mathrm{~mm}$ above the burner centerline.

Simultaneous planar laser induced florescence (PLIF) images of formaldehyde molecules $\left(\mathrm{CH}_{2} \mathrm{O}\right)$ and Hydroxyl radicals $(\mathrm{OH})$ were used to investigate the structural features of highly turbulent flames. These images were acquired by two Andor iStar intensified CCD cameras binned $(2 \times 2)$ to 512 x 512 pixels. Formaldehyde $\left(\mathrm{CH}_{2} \mathrm{O}\right)$ was excited by the third harmonic of a Spectra-Physics Nd:YAG laser, which produced a 355-nm with pulse energies of approximately $135 \mathrm{~mJ}$. The returning $\mathrm{CH}_{2} \mathrm{O}$ fluorescence was filtered using a high and low pass filter (CG385 and BG3, respectively) transmitting wavelengths between 385 and $490 \mathrm{~nm}$. OH radicals were excited by pumping a Sirah dye laser with the second harmonic (near $532 \mathrm{~nm}$ ) from a Spectra-Physics Nd:YAG laser. The dye laser was tuned such that it produced a 564.14-nm beam, which was frequency doubled via a BBO crystal to $282.07 \mathrm{~nm}$ to excite the $\mathrm{P}_{1}(5)$ transition of $\mathrm{OH}^{25}$. The typical pulse energies at $282.07 \mathrm{~nm}$ were roughly $4.5 \mathrm{~mJ}$. The camera capturing $\mathrm{OH}$ fluorescence was equipped with a bandpass filter centered at $310+/-5 \mathrm{~nm}$. Gate times for both cameras were limited to $100 \mathrm{~ns}$ and the laser pulses were separated by $200 \mathrm{~ns}$ to avoid cross-talk ${ }^{26}$. A diagram depicting the simultaneous PLIF imaging setup is provided in Figure 4. Note that for the sake of clarity only one set of sheet forming optics is shown; however, the $\mathrm{OH}$ and $\mathrm{CH}_{2} \mathrm{O}$ laser sheets were formed with two separate sets of sheet-forming optics, and were overlapped before being focused over the burner centerline. 


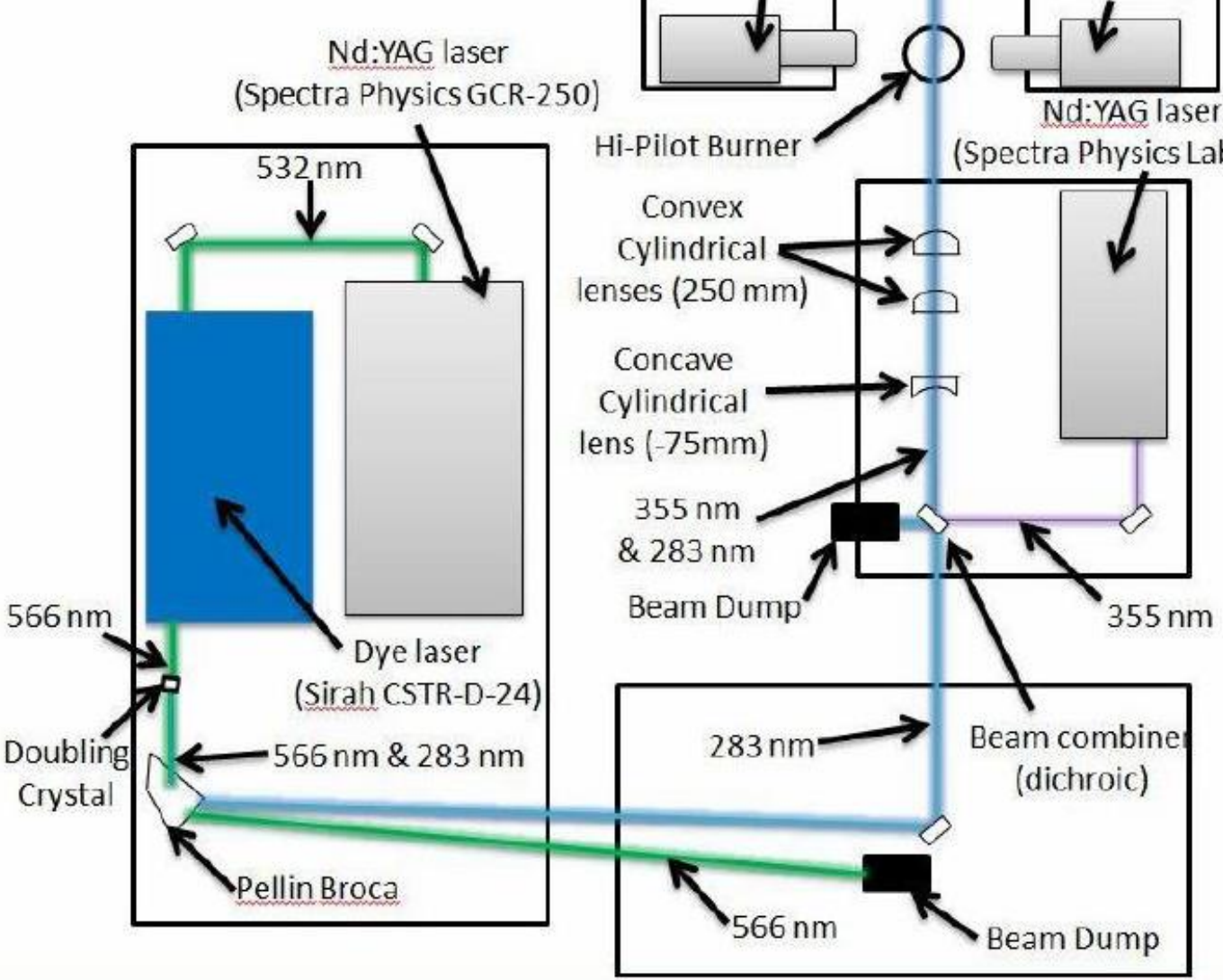

Figure 4. Schematic of the simultaneous $\mathrm{CH}_{2} \mathrm{O}-\mathrm{OH}$ PLIF system.

\section{Image post processing}

In this study, the reaction zone thickness is defined as the width of the $\mathrm{CH}_{2} \mathrm{O}-\mathrm{OH}$ overlap layer at $50 \%$ of its maximum value (FWHM). Previous studies ${ }^{27-40}$ have also used the product of $\mathrm{OH}$ and $\mathrm{CH}_{2} \mathrm{O}$ images to define the reaction layer. This is because reactions between $\mathrm{OH}$ and $\mathrm{CH}_{2} \mathrm{O}$ are one of the primary sources of formyl radicals (HCO) in methane-air flames ${ }^{27,34}$. Since $\mathrm{HCO}$ is removed much quicker than it is formed its production rate is proportional to $[\mathrm{OH}] \mathrm{x}\left[\mathrm{CH}_{2} \mathrm{O}\right]^{34}$. Furthermore, since $\mathrm{HCO}$ correlates well with heat release rate in methane-air flames ${ }^{28}$, so does $[\mathrm{OH}] \mathrm{x}[\mathrm{CH} 2 \mathrm{O}]^{27,34}$. Moreover, an advantage of using $\mathrm{OH}$ and $\mathrm{CH}_{2} \mathrm{O}$ to define the reaction layer is that one can also obtain information about the preheat zone. Namely, $\mathrm{Li}$ et al. ${ }^{41}$ showed that $\mathrm{CH}_{2} \mathrm{O}$ is a decent marker of the preheat zone. Thus in addition to reaction zone thicknesses, preheat zone thicknesses were also obtained in this study. Here, the preheat zone thickness is defined as the width of the $\mathrm{CH}_{2} \mathrm{O}$ signal from its $35 \%$ point on the reactant side to the leading edge of the reaction zone (defined above as the half-maximum value on the reactant side).

However, prior to making any thickness measurements, several steps were taken to improve the quality of the $\mathrm{OH}$ and $\mathrm{CH}_{2} \mathrm{O}$ images. First background noise was removed from the raw $\mathrm{OH}$ and $\mathrm{CH}_{2} \mathrm{O}$ images, which were subsequently corrected for variations in laser sheet intensity. After this adjustment a combination of median and levelset filters ${ }^{42,43}$ were applied to the images to enhance their signal-to-noise ratios (SNRs). Following this filtering the $\mathrm{OH}$ images were transformed so that they would register to the $\mathrm{CH}_{2} \mathrm{O}$ images. The transform matrix that enabled this registry was produced by identifying the matching points on a target image captured by each camera. That is, each camera imaged a double-sided target (consisting of crosses printed on one side of a thin transparent sheet) that was aligned with the laser sheets. Following this transformation, the pixel-by-pixel multiplication of these modified images was performed. 
An example of how the reaction zone is obtained from filtered $\mathrm{OH}$ and $\mathrm{CH}_{2} \mathrm{O}$ images is provided in Figure 5 below.
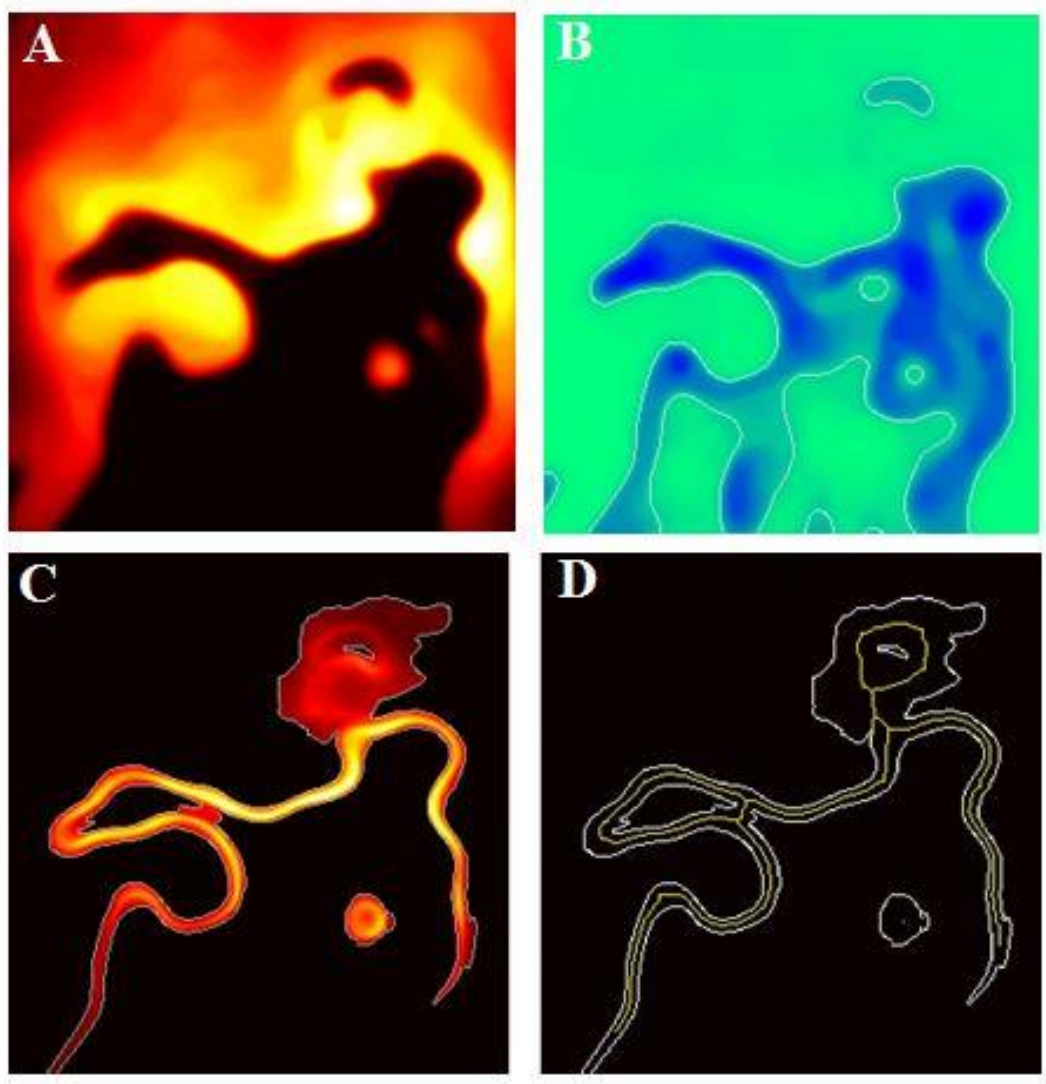

Figure 5. (A) and (B) display filtered, instantaneous PLIF image of $\mathrm{OH}$, and $\mathrm{CH}_{2} \mathrm{O}$, respectively. (C) exhibits the locally thresholded pixel-by-pixel product of the $\mathrm{OH}$ and $\mathrm{CH}_{2} \mathrm{O}$ images presented in (A) and (B). While (D) displays the edge (in white) and the skeleton (in yellow) associated with the reaction zone shown in (C).

Panel (c) of Figure 5 is a prime example of how the reaction zone can assume any arbitrary shape and orientation. Due to this vast variation in shape and orientation the full-width at half-maximum (FWHM) of the product images is obtained by implementing a local thresholding method.

The thresholding method first implements a global threshold, which was generated based on the standard deviation of the signal. Specifically, all pixels with an intensity count greater than twice the standard deviation of the image's intensity were set to one, while the rest were set to zero. A skeleton (such as the one depicted by the yellow line in Figure 5D) is then formed from this newly binarized image. This skeleton is used for local thresholding, since it represents a first guess at where the flame lies. Each pixel in the product image is compared to the nearest skeleton pixel; that is, each pixel is thresholded not relative to a field constant, but to the value of a point in the image where a flame is believed to be located. The thresholding process is repeated two additional times, using the previous result as the input to the next iteration. In this way, thresholding the image was done locally instead of globally, which helps to avoid errors introduced by naturally occurring variations in the intensity of the reaction layers throughout the FOV.

Once the product images were properly thresholded an average reaction and preheat zone thickness was calculated for each image as follows. First, the distance between each pixel on the skeleton and the nearest pixel on an edge of the reaction zone was determined. Then, these distances where multiplied by a factor of two to account for the fact that the skeleton lies along the center of the reaction zones. Finally, summing these distances over the whole skeleton in a particular image and subsequently dividing this summation by the length of that skeleton produced an average thickness value for that image. The average preheat zone thickness for a specific image was computed in a 
similar fashion; the only difference being that the $\mathrm{CH}_{2} \mathrm{O}$ signal was thresholded at $35 \%$ of its local maximum and then modified to exclude reaction zone regions (i.e. the $\mathrm{CH}_{2} \mathrm{O}-\mathrm{OH}$ overlap layers were subtracted from the $\mathrm{CH}_{2} \mathrm{O}$ signal).

\section{Results}

This section provides details about flow-field measurements and both qualitative and quantitative flame properties for each of the four cases described in Table 1 above.

\section{A. LDV Flow-field Characterization}

Turbulence level and integral scale measurements were made with the laser velocimeter system and the results are listed in Table 1. For each case in the test matrix, 4-6 LDV measurements consisting of 500,000 samples each were collected. Autocorrelations were computed using the normalized slotting method of Mayo et al. ${ }^{44,45}$. The resulting averaged autocorrelation functions for cases $1 \mathrm{a}-4 \mathrm{a}$ and $1 \mathrm{~b}-4 \mathrm{~b}$ are shown in Figure 6. The autocorrelation functions for case $1 c-4 c$ were omitted because they are nearly the same as those of cases $1 a-4 a$.

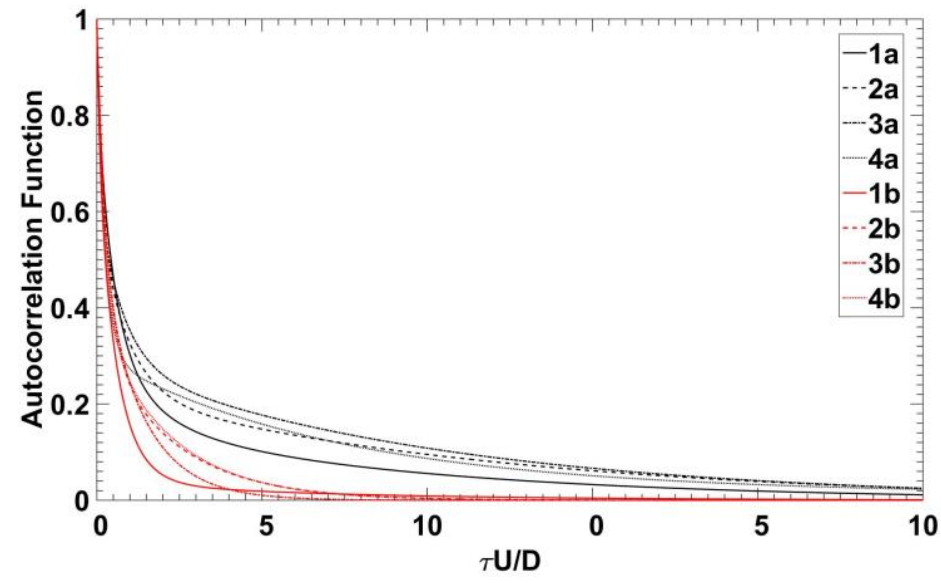

Figure 6. Autocorrelation function for cases $1 \mathrm{a}-4 \mathrm{a}$ and $1 \mathrm{~b}-4 \mathrm{~b}$.

The corresponding length scales, defined as the integral of the autocorrelation curve, are given in Table 1. Figure 6 demonstrates that by employing the separate turbulence generator plates, the HPB can produce a relatively large range of integral length scales. The integral length scales for cases $1 \mathrm{a}-4 \mathrm{a}, 1 \mathrm{~b}-4 \mathrm{~b}$, and $1 \mathrm{c}-4 \mathrm{c}$ were found to range between 16 and $31 \mathrm{~mm}, 6$ and $12 \mathrm{~mm}$, and 7.5 and $37 \mathrm{~mm}$, respectively.

Note that integral length scales cannot be directly obtained from LDV measurements. LDV data can provide integral time scales, however, which are commonly converted to a length scale using Taylor's "frozen turbulence" hypothesis. This simplification holds that in the case of very small turbulent fluctuations $\mathrm{u}^{\prime}<<\mathrm{U}_{0}$, the mean velocity provides a linear transformation between length and time scales. Thus, in the frozen flow regime,

$$
\lambda(\mathrm{x})=\tau(\mathrm{t}) * \mathrm{U}_{0}
$$

In Eq. (9), $\tau(t)$ is the integral of the autocorrelation, i.e. the area under the curve for each case in Figure 6. However, in the event of very large turbulent fluctuations, this linear approach is no longer valid. Flows issuing from the HPB have turbulence intensities exceeding $40 \%$ in some cases, and thus $\mathrm{u}^{\prime} \sim \mathrm{U}_{0}$ and a more general transformation is required. Following the approach of $\mathrm{Wu}$ and Patterson ${ }^{46,47}$, the relation between length scale and time scale for a flow with only a single component of mean velocity $\left(\mathrm{U}_{0}\right.$, the centerline velocity, with zero mean radial velocity) and isotropic turbulence $\left(\mathrm{u}_{1}{ }^{\prime}=\mathrm{u}_{2}{ }^{\prime}=\mathrm{u}_{3}{ }^{\prime}=\mathrm{u}^{\prime}\right)$ is:

$$
\lambda(\mathrm{x})=\tau(\mathrm{t}) * \mathrm{U}_{0} \sqrt{1+5 \frac{u^{\prime}}{\mathrm{U}_{0}}}
$$


This modification to the traditional method of converting LDV time scales to length scales avoids the simplification inherent with Taylor's hypothesis. The corresponding integral length scale measurements are given in Table 1.

\section{B. Laminar flame measurements}

Both numerical and experimental measurements of laminar flames were conducted in this study. The numerical analysis was carried out by running CHEMKIN simulations of freely propagating methane - air flames with $\phi=$ 0.75 and 1.05. Profiles of temperature, various species, and heat release from the lean simulation are provided in Figure 7.

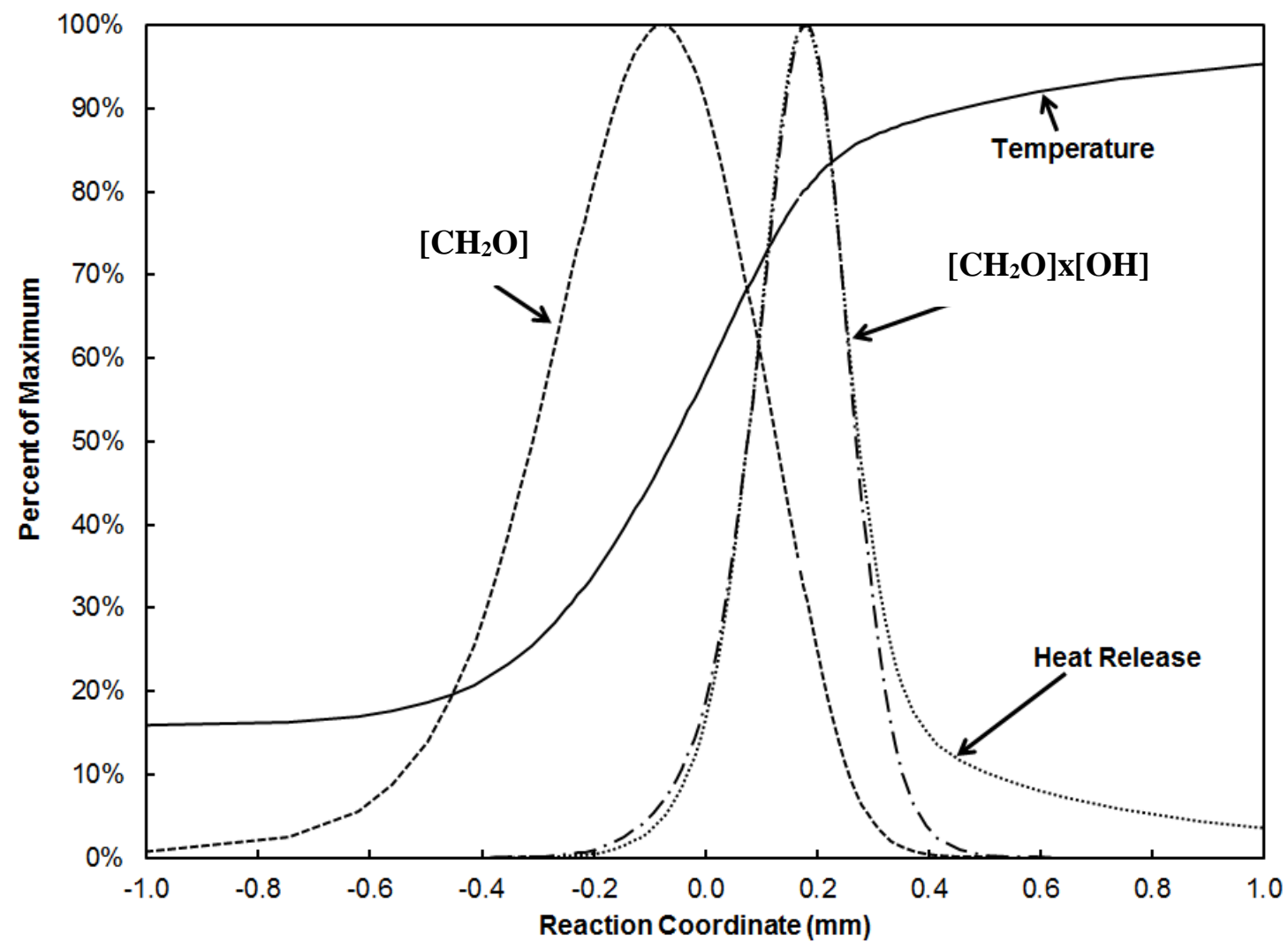

Figure 7. CHEMKIN laminar flame $(\phi=0.75)$ computations showing that $\mathrm{CH}_{2} \mathrm{O}$ marks the preheat zone while the $\mathrm{CH}_{2} \mathrm{O}-\mathrm{OH}$ overlap layer marks the reaction zone.

As discussed above, the reaction zone thickness is defined as the FWHM of the layer derived from the product of $\mathrm{OH}$ and $\mathrm{CH}_{2} \mathrm{O}$. Based on this definition, CHEMKIN gives reaction zone thicknesses $\left(\delta_{\mathrm{RZ}, \mathrm{LC}}\right)$ of 0.18 and 0.15 $\mathrm{mm}$ for the lean and rich cases, respectively. Also, in this study the preheat zone thickness is defined as the width of the $\mathrm{CH}_{2} \mathrm{O}$ signal from where it exceeds $35 \%$ of its maximum value on the reactant side to the leading edge of the reaction zone. A value of $35 \%$ was chosen for the leading edge of the preheat zone because CHEMKIN shows that at this location the gas temperature is $550 \mathrm{~K}$. This temperature was selected to be the leading edge of the flame front. The un-stretched, laminar value of the preheat zone thickness $\left(\delta_{\mathrm{PH}, \mathrm{LC}}\right)$ for flames with $\phi=0.75$ and 1.05 , were computed by CHEMKIN to be 0.36 and $0.24 \mathrm{~mm}$, respectively.

To demonstrate their validity, the diagnostics and post processing techniques used in this study were applied to laminar flames. Simultaneous $\mathrm{OH}$ and $\mathrm{CH}_{2} \mathrm{O}$ images from lean and rich laminar flames are displayed in Figure 8. 

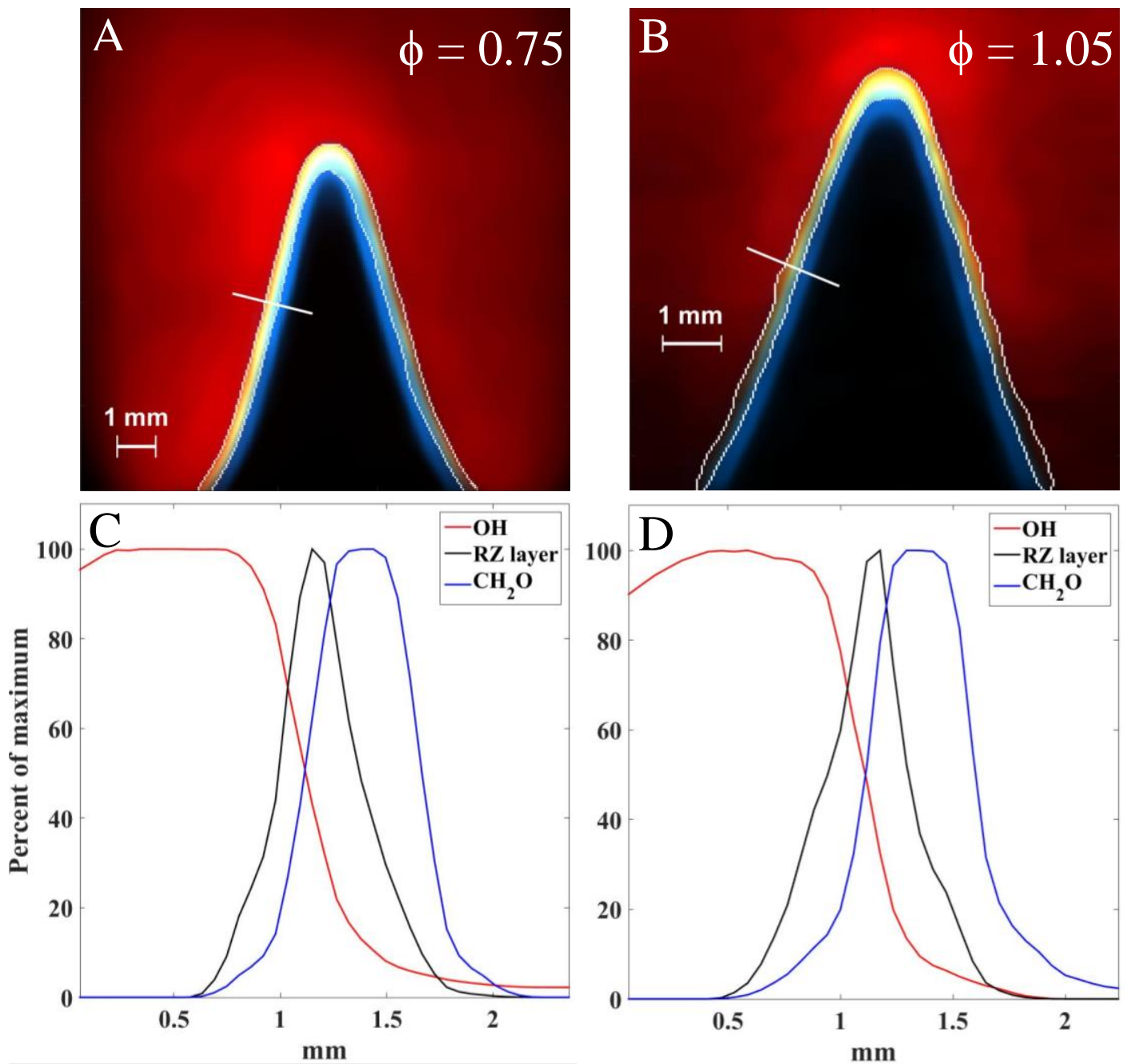

Figure 8. Panels (A) and (B) show PLIF images of $\mathrm{CH}_{2} \mathrm{O}$ (blue), $\mathrm{OH}$ (red), and reaction zone (yellow) for lean and rich laminar flames, respectively. Panels (C) and (D) display profiles of $\mathrm{OH}, \mathrm{CH}_{2} \mathrm{O}$, and the reaction layer along the white lines in Panels (A) and (B), respectively.

In Figure 8, red and blue regions mark $\mathrm{OH}$ and $\mathrm{CH}_{2} \mathrm{O}$ PLIF signals, respectively, while yellow regions represent the reaction layers. On average the reaction layer thicknesses $\left(\delta_{\mathrm{RZ}, \mathrm{L}}\right)$ computed using the automated code described in section II.C above were 0.39 and $0.38 \mathrm{~mm}$ for the lean and rich flames, respectively. Furthermore, the average preheat layer thicknesses $\left(\delta_{\mathrm{PH}, \mathrm{L}}\right)$ computed from the actual laminar flames are 0.42 and $0.39 \mathrm{~mm}$ for the lean and rich flames, respectively. These values are up to 2.5 times as thick as those measured from the CHEMKIN simulations. Possible reasons for this discrepancy are as follows: (1) the finite laser sheet thickness; (2) the limited image resolution; (3) the filters applied to the images; and (4) differences between the actual laminar flame configuration and idealistic one simulated by CHEMKIN. Therefore, in order to properly display the affect turbulence has on reaction and preheat layers, the measured laminar thickness values are used to normalize those acquired from turbulent flames.

Figures $8 \mathrm{C}$ and $8 \mathrm{D}$ display the $\mathrm{OH}, \mathrm{CH}_{2} \mathrm{O}$, and reaction layer profiles taken along the white lines in Figures $8 \mathrm{~A}$ and $8 \mathrm{~B}$, respectively. The FWHM of the reaction layer profiles is 0.395 and $0.375 \mathrm{~mm}$ for the lean and rich flames, respectively. Additionally, using the definition of the preheat layer thickness described above, the profiles in Figure 8C and 8D give preheat layer thicknesses of 0.422 and $0.394 \mathrm{~mm}$, respectively. The fact that these values are within $1 \%$ of the average values computed over the whole data sets demonstrates the robustness of our method for determining average layer thicknesses. 


\section{Turbulent flame results}

This section discusses patterns identified in instantaneous PLIF images of $\mathrm{CH}_{2} \mathrm{O}$ and $\mathrm{OH}$ as well as several measurements made from these images.

\section{a. $\mathrm{OH}, \mathrm{CH}_{2} \mathrm{O}$, and $\mathrm{CH}_{2} \mathrm{O}-\mathrm{OH}$ overlap images}

To provide a holistic view of the lean flames, a single large FOV $\left(22 \times 36 \mathrm{~mm}^{2}\right)$ PLIF image is displayed for cases $1 \mathrm{a}-4 \mathrm{a}$ in Figure 9 below. Note however that in general this FOV was not large enough to image the flame from base to tip.
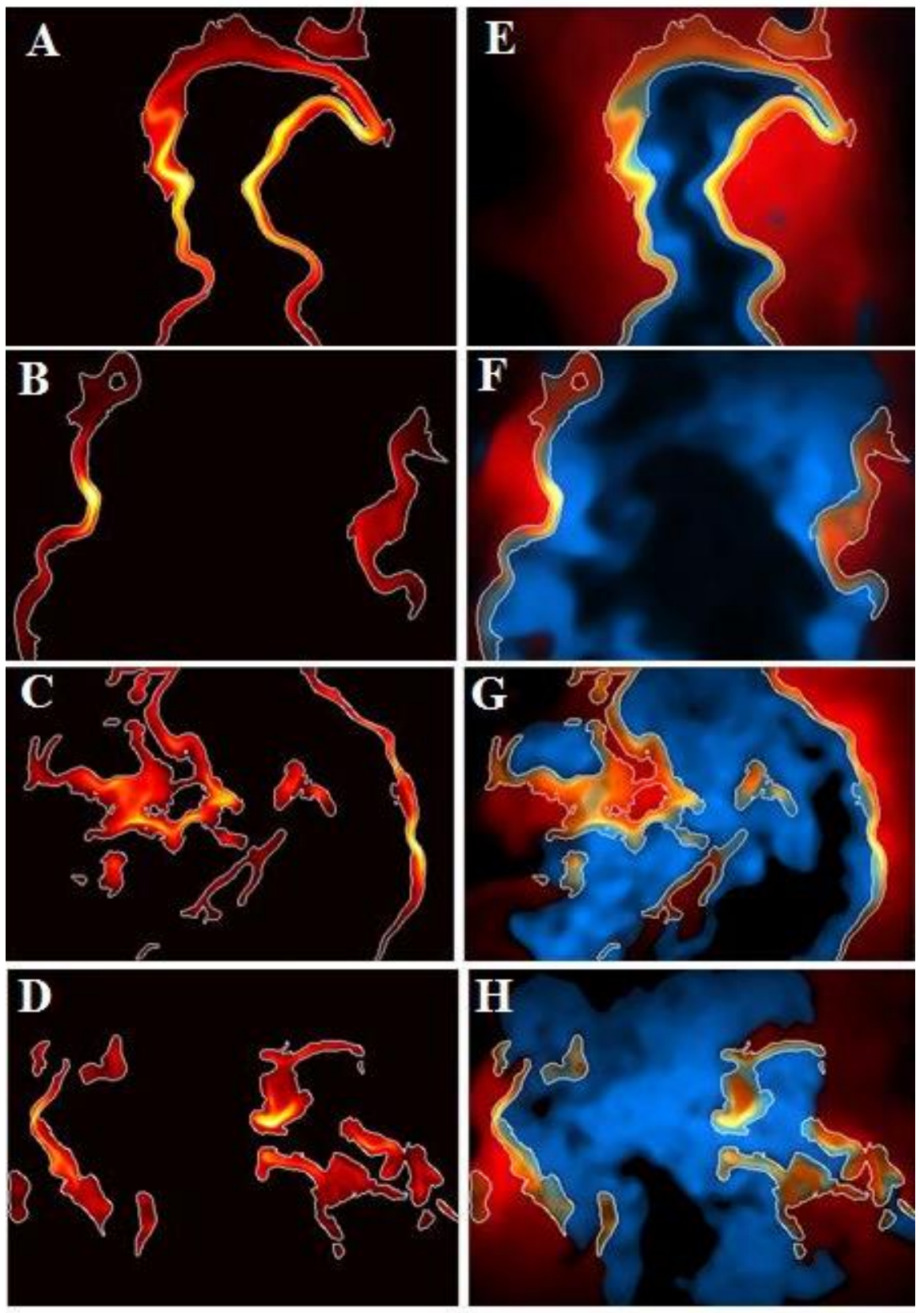

Figure 9. Panels (A) - (D) display post-processed, instantaneous reaction zones within a $22 \times 36 \mathrm{~mm}^{2}$ field of view for cases $1 \mathrm{a}-4 \mathrm{a}$, respectively. Panels (E) - $(\mathrm{H})$ show PLIF images of $\mathrm{CH}_{2} \mathrm{O}$ (blue), $\mathrm{OH}$ (red), and reaction zone (yellow) for cases $1 \mathrm{a}-4 \mathrm{a}$, respectively. Note that the lower edge of each image is $5 \mathrm{~mm}$ above the burner and the centerline of each image is the burner's centerline. 
Similar, large FOV images of the rich flames (cases 1c $-4 c$ ) are displayed in Figure 10.

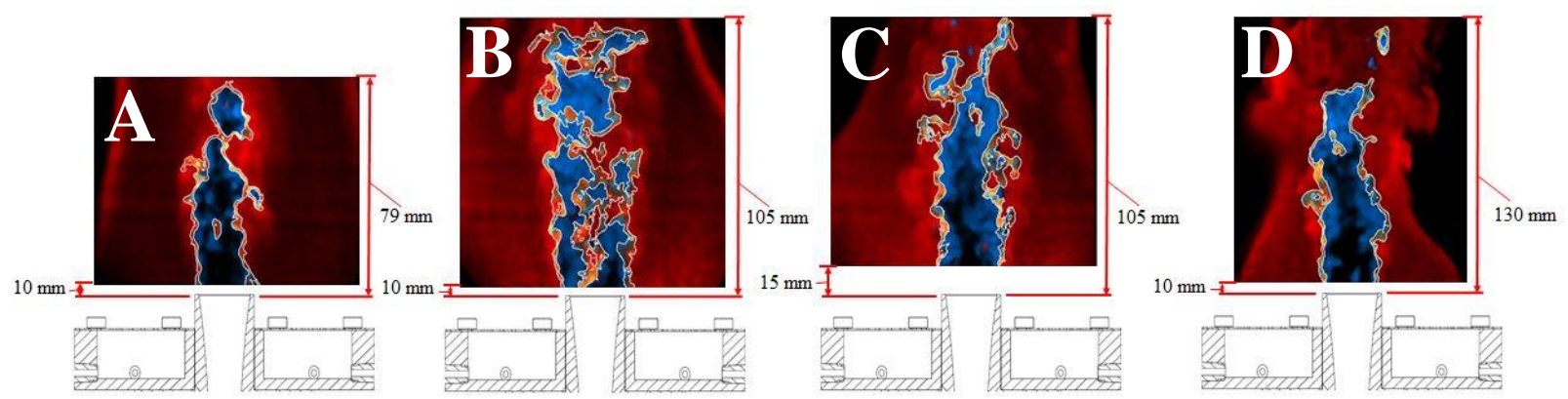

Figure 10. Panels (A) - (D) display PLIF images of $\mathrm{CH}_{2} \mathrm{O}$ (blue), $\mathrm{OH}$ (red), and reaction zone (yellow) for cases 1c $-4 \mathrm{c}$, respectively.

One advantage of these large FOV images, is that they clearly show whether or not ambient air comes in contact with the reaction layers. Specifically, when blue regions $\left(\mathrm{CH}_{2} \mathrm{O}\right)$ are not surrounded by red regions $(\mathrm{OH})$, it is likely that room-air entrainment has occurred. Such entrainment could substantially alter the combustion mode (e.g. cause local extinction). Figure 10 suggests that the large-pilot-flame does a good job of mitigating room-air entrainment. However, Figures $9 \mathrm{G}$ and $9 \mathrm{H}$ indicate that the small-pilot-flame does not always protect the primary flame from room-air entrainment.

The blue regions in the right panels of Figure 9 and in all panels of Figure 10 show that the preheat zone thickness tends to increase with increasing turbulence intensity. Additionally, Figures 9 and 10 indicate that the preheat zone thickness increases with height above burner. This trend is particularly clear in panels $(\mathrm{G})$ and $(\mathrm{C})$ of Figures 9 and 10, respectively. Here, for heights greater than $20 \mathrm{~mm}$ above the burner, $\mathrm{CH}_{2} \mathrm{O}$ is found throughout the entire central region of the flame. Similar results were also observed by Zhou et al. in a porous-plug/jet burner ${ }^{17,18}$. Variations in preheat zone thickness with turbulence intensity and height above burner are discussed in greater detail in section III.C.b below.

In contrast to the preheat zone, trends associated with the reaction zone thickness are more difficult to extract from Figures 9 and 10. This is because segments of both thick and relatively thin (i.e. $\delta_{\mathrm{RZ}, \mathrm{T}} \leq 2 * \delta_{\mathrm{RZ}, \mathrm{L}}$ ) reaction zones can be seen throughout the entire FOV in each sub-image presented above. In fact, the appearance of the observed reaction zones can best be described as resembling "chicken noodle soup." That is, relatively thin, "noodle-like" reaction zones are generally accompanied by thicker "chunky-chicken-like" reaction regions in any given instantaneous image. Take for example Figures 9C, 9D, 10B, and 10D where blobby, distributed reaction regions are intermixed with relatively long and thin reaction zones. Furthermore, as will be seen in Figures $12-16$, even though some of these flames are subjected to extreme turbulence levels and the stabilizing pilot-flame is drastically altered, this "chicken noodle soup" reaction zone structure persists across all of the cases considered here. These observations suggest that the classical regime diagrams ${ }^{19,20,22}$ may be unable to accurately forecast the structural appearance of reaction layers in extremely turbulent flames.

To more finely resolve flame structures and to obtain quantitative data, the instantaneous PLIF images were acquired from relatively small FOVs: $20 \times 20 \mathrm{~mm}^{2}$ (cropped to $13 \times 20 \mathrm{~mm}^{2}$ ) for cases $1 \mathrm{a}-4 \mathrm{a}$ and $1 \mathrm{~b}-4 \mathrm{~b}$ and $30 \mathrm{x}$ $30 \mathrm{~mm}^{2}$ for cases $1 \mathrm{c}-4 \mathrm{c}$. These smaller FOVs gave image resolutions of $40 \mu \mathrm{m} /$ pixel for cases $1 \mathrm{a}-4 \mathrm{a}$ and $1 \mathrm{~b}-4 \mathrm{~b}$ and $59 \mu \mathrm{m} /$ pixel for cases $1 \mathrm{c}-4 \mathrm{c}$. Images of cases $1 \mathrm{a}-4 \mathrm{a}$ and $1 \mathrm{~b}-4 \mathrm{~b}$ were taken from an interrogation region near the exit of the HPB (lower zone); additionally, cases $2 \mathrm{a}-4 \mathrm{a}$ were investigated at a downstream location (upper zone). The relative locations of these zones are depicted in Figure 10. 


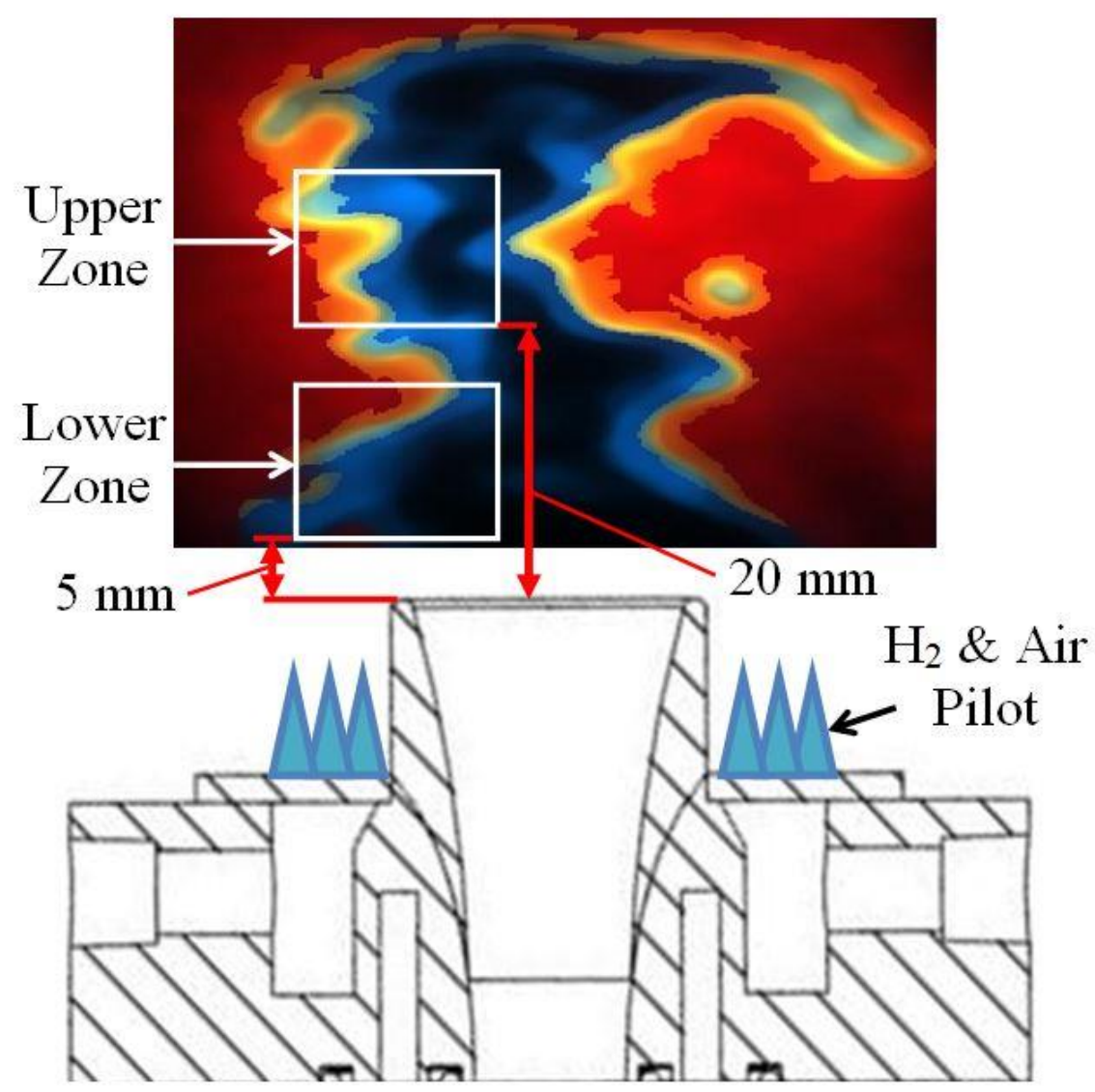

Figure 11. Diagram depicting the relative locations of the upper and lower zones. Note that the field of view for this image is $22 \times 36 \mathrm{~mm}^{2}$.

As Figure 11 shows, the lower and upper zones span regions between $5 \mathrm{~mm}$ and $18 \mathrm{~mm}$ and between $20 \mathrm{~mm}$ and $33 \mathrm{~mm}$ above the burner, respectively. The zone in which images of cases $1 \mathrm{c}-4 \mathrm{c}$ were acquired is similar to the upper zone. Namely, this zone covers a region that spans 28 to $58 \mathrm{~mm}$ above the burner. Since this zone overlaps with a substantial portion of the upper zone, for brevity, it will also be referred to as the upper zone. Sample images acquired from: (1) the lower zones of cases $1 b$ and $2 b$; (2) the upper zones of cases $2 a$ and $4 a$; and (3) the upper zone of cases $1 c-4 c$ are displayed in Figures $12-16$, respectively. Images from the other four cases are excluded for the sake of brevity and because they exhibit similar traits as the images below. 


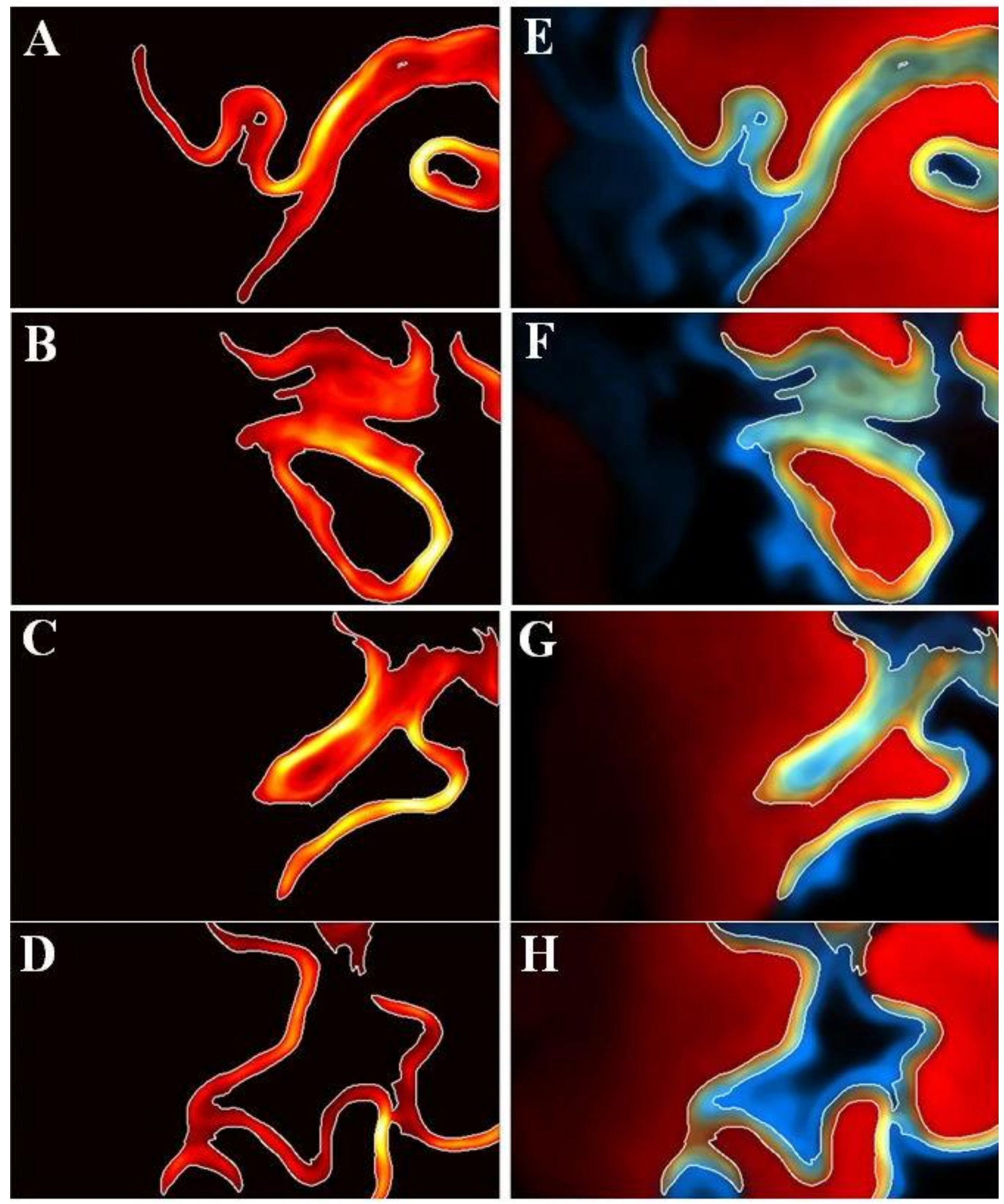

Figure 12. Representative images from the lower zone of case 1b. Post-processed, instantaneous images of the derived reaction zone are displayed in panels (A) - (D). Panels (E)-(F) display a compilation of all three signals, where blue indicates $\mathrm{CH}_{2} \mathrm{O}$ signal, red indicates $\mathrm{OH}$ signal, and yellow indicates the reaction zone. 

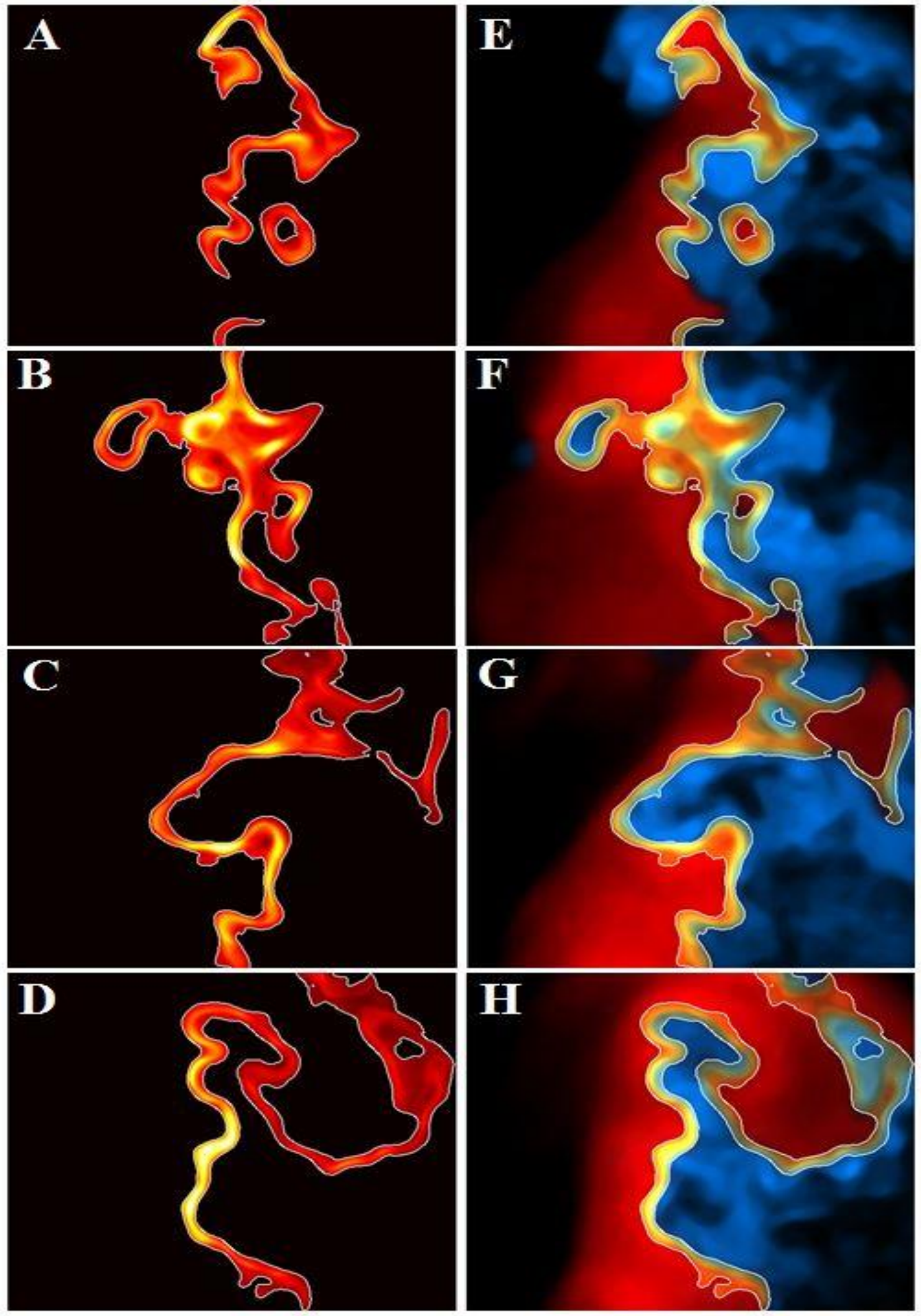

Figure 13. Representative images from the lower zone of case $2 \mathrm{~b}$. Post-processed, instantaneous images of the derived reaction zone are displayed in panels (A) - (D). Panels (E)-(F) display a compilation of all three signals, where blue indicates $\mathrm{CH}_{2} \mathrm{O}$ signal, red indicates $\mathrm{OH}$ signal, and yellow indicates the reaction zone. 

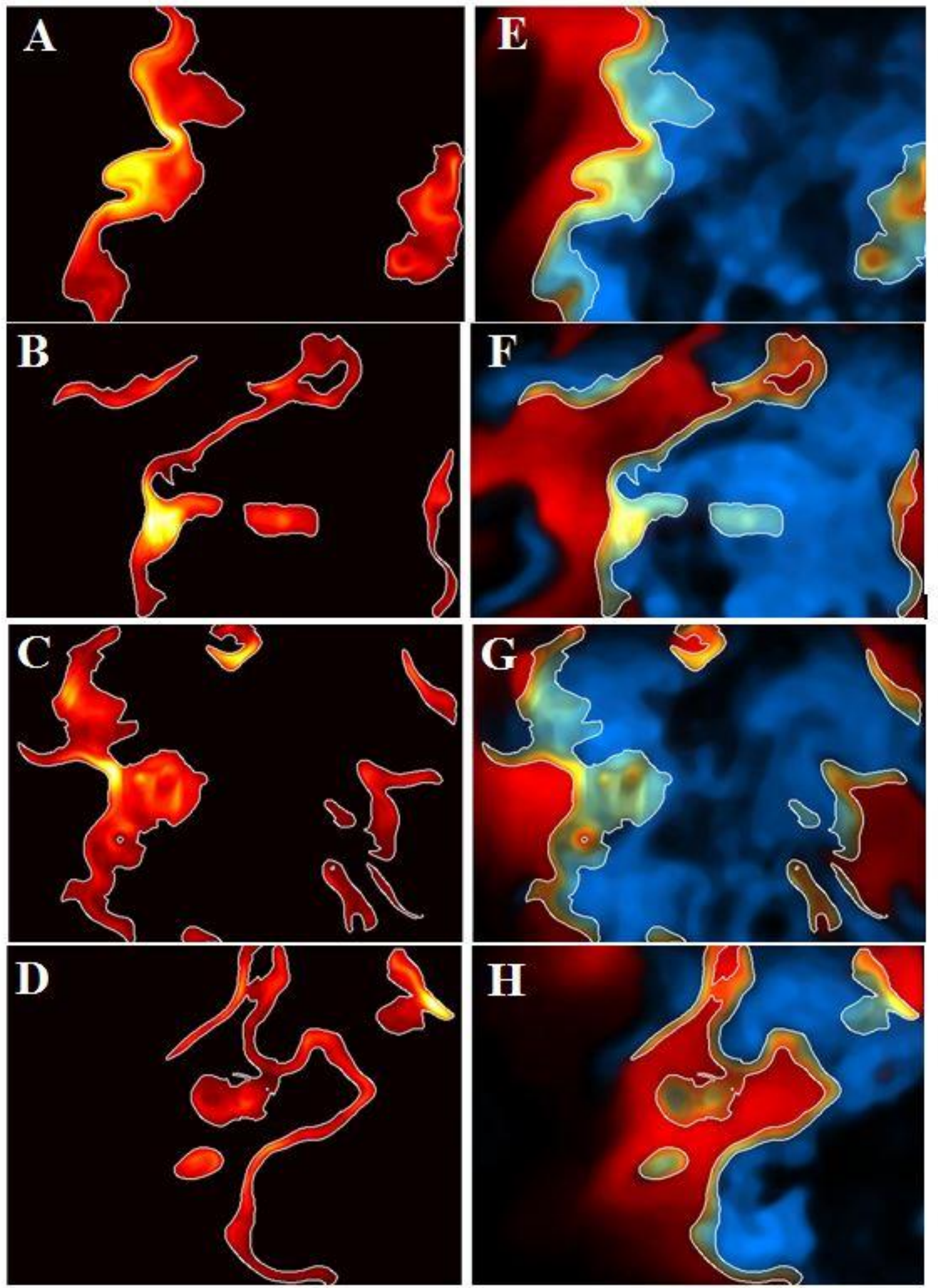

Figure 14. Representative images from the upper zone of case 2a. Post-processed, instantaneous images of the derived reaction zone are displayed in panels (A) - (D). Panels (E)-(F) display a compilation of all three signals, where blue indicates $\mathrm{CH}_{2} \mathrm{O}$ signal, red indicates $\mathrm{OH}$ signal, and yellow indicates the reaction zone. 

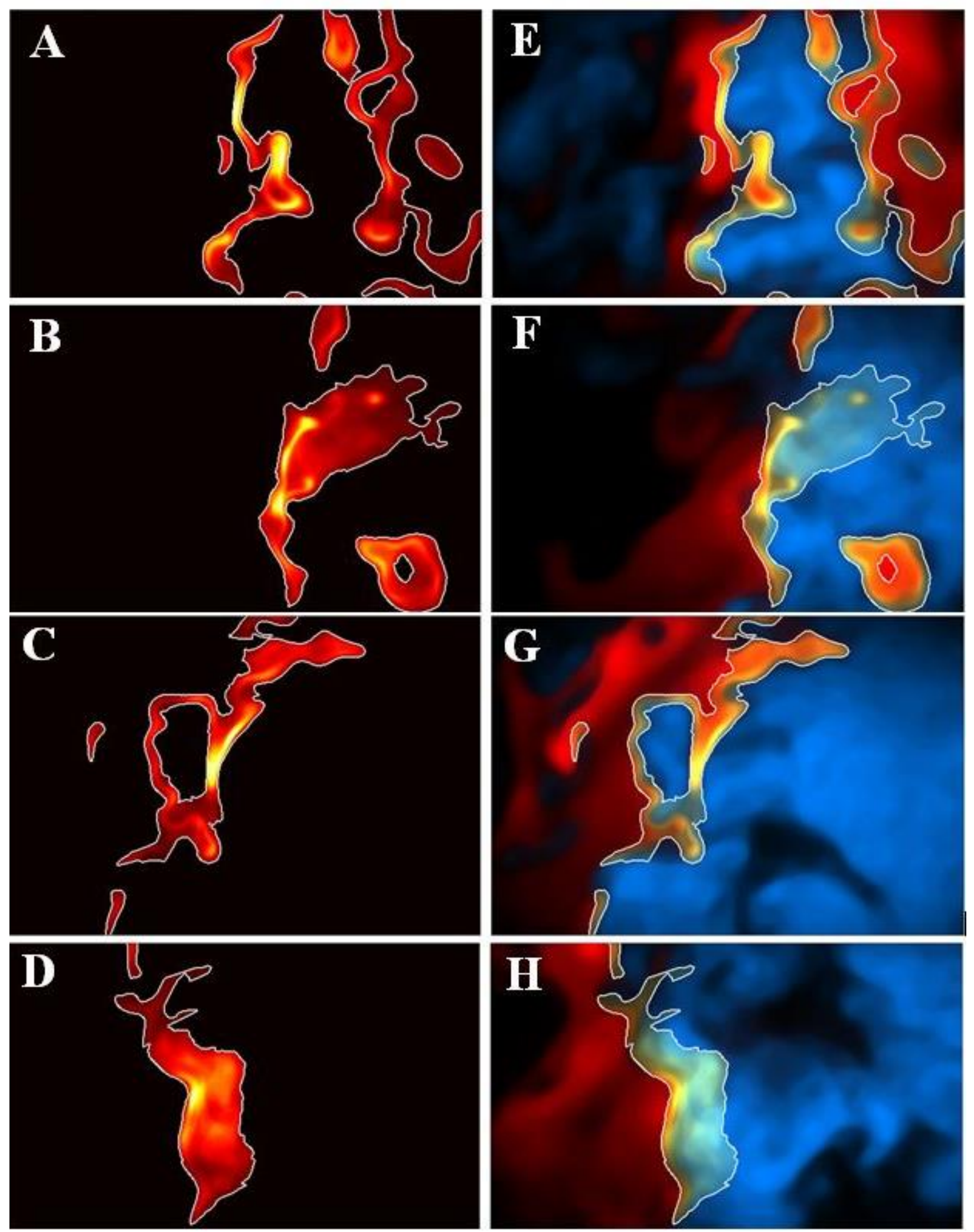

Figure 15. Representative images from the upper zone of case 4a. Post-processed, instantaneous images of the derived reaction zone are displayed in panels (A) - (D). Panels (E)-(F) display a compilation of all three signals, where blue indicates $\mathrm{CH}_{2} \mathrm{O}$ signal, red indicates $\mathrm{OH}$ signal, and yellow indicates the reaction zone. 

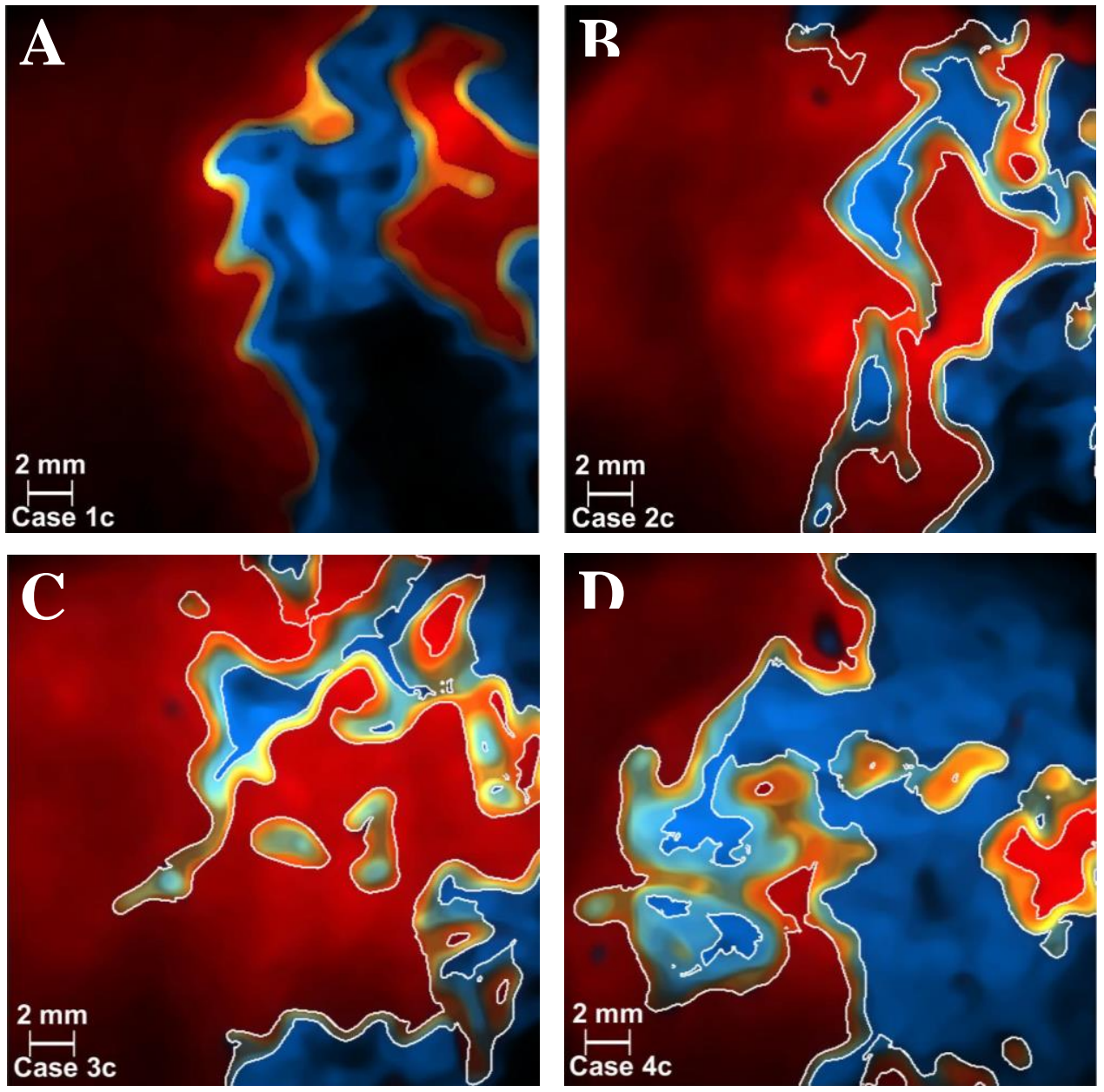

Figure 16. Representative images from cases $1 \mathrm{c}-4 \mathrm{c}$ in panels (A) - (D), respectively, where blue indicates $\mathrm{CH}_{2} \mathrm{O}$ signal, red indicates $\mathrm{OH}$ signal, and yellow indicates the reaction zone.

These higher resolution images emphasize the patterns seen in Figures 9 and 10. That is, the preheat zone thickness increases with increasing turbulence intensity while the reaction zone layers take on a variety of shapes. Specifically, while images taken from the lower zone of case 1b's flame (shown in Figures 12E - 12H) exhibit preheat zones that are only slightly larger than the reaction zones, images from the upper zone of case 4a (shown in Figures $15 \mathrm{E}-15 \mathrm{H}$ ) and from case $4 \mathrm{c}$ (shown in Figure 16D) show preheat zones that completely fill the flame brush. This trend of increasing preheat zone thickness with increasing turbulence intensity is discussed further in section III.C.b below.

As alluded to above, unlike the preheat zones, trends associated with the reaction zones cannot be easily extracted from Figures $12-16$. Take for example case $1 \mathrm{~b}$, which was the least turbulent case considered and, based on its boundary conditions, is classified into the "thin reaction zone" regime (see Figure 1). Nevertheless, Figures $12 \mathrm{~B}$ and $12 \mathrm{C}$ clearly show that it is possible for this case's reaction zones to become thick and distributed. On the other hand, case $4 \mathrm{a}$ was the most turbulent case considered and, according to its measured boundary conditions, falls into the "distributed reaction zone" regime (see Figure 1). Yet, relatively thin reaction zone structures are observed in Figures 15A and 15C. Furthermore, comparing Figures $12-15$ to Figure 16 suggests that the stabilizing pilot doesn't play a major role in determining the structural features of the reaction layers (at least not at these axial locations). Additionally, Figures 13, 14, and 16 demonstrate that both thick and thin reaction regions exist over a wide range of turbulence levels. The fact that each case exhibits a soupy mixture of thin and distributed reaction zones leads to average reaction zone thicknesses that vary only slightly with dramatic changes in $\mathrm{Re}_{\mathrm{T}}, \mathrm{Da}_{\mathrm{T}}$, and $\mathrm{Ka}_{\mathrm{T}}$. Average reaction and preheat zone thicknesses are presented and discussed in the following section. 


\section{b. Average thicknesses of preheat and reaction zones}

Average preheat and reaction zone thicknesses were determined for each of the $\mathrm{CH}_{2} \mathrm{O}$ PLIF images and the product of the $\mathrm{OH}$ and $\mathrm{CH}_{2} \mathrm{O}$ PLIF images, respectively. Over $250 \mathrm{PLIF}$ image pairs of $\mathrm{OH}$ and $\mathrm{CH}_{2} \mathrm{O}$ were acquired for each case and the details of how average thicknesses were computed from these images are provided in section II.C above. The datum points in Figure 17 below represent an ensemble average of the preheat zone thicknesses over all images taken for each case.

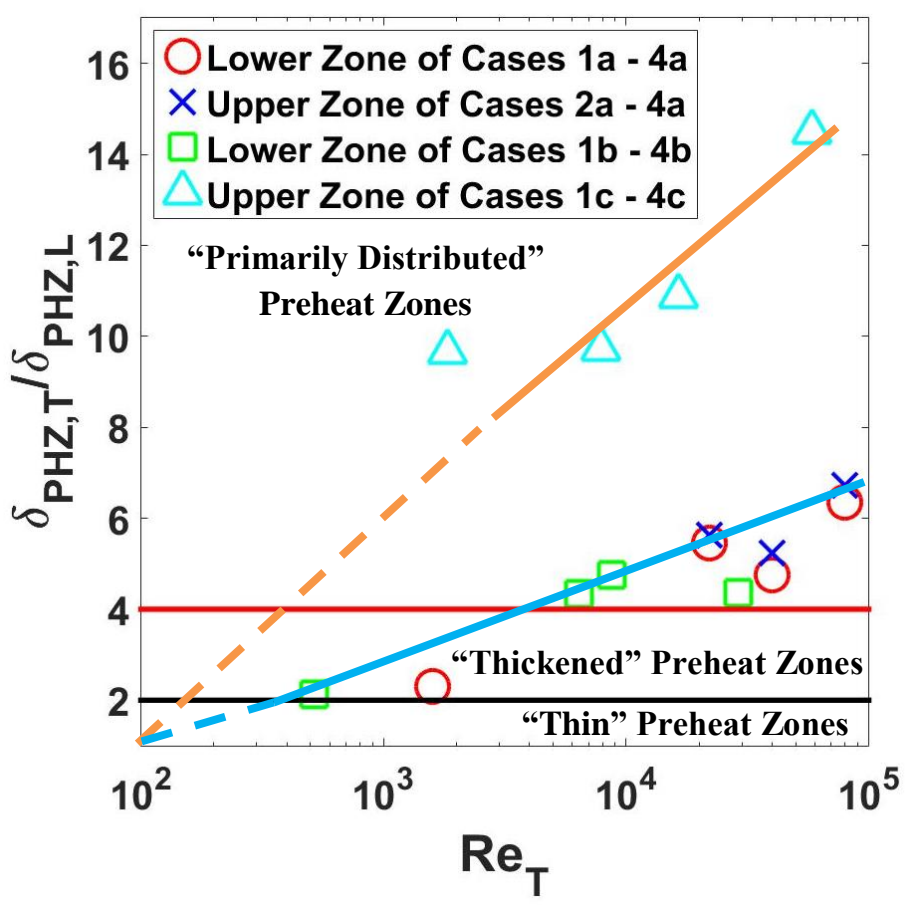

Figure 17. Average turbulent preheat zone thickness normalized by values measured in laminar flames $(0.42 \mathrm{~mm}$ for $\phi=0.75$ and $0.39 \mathrm{~mm}$ for $\phi=1.05)$ as a function of $\operatorname{Re}_{\mathrm{T}}$.

Figure 17 clearly shows that the preheat zone thickness increases with turbulence Reynolds number. However, the linear trend displayed by the results in Figure 17 suggest that the average preheat zone thickness is roughly a logarithmic function of $\mathrm{Re}_{\mathrm{T}}$, and hence possesses asymptotic qualities. That is, the average preheat zone thicknesses level off for $\mathrm{Re}_{\mathrm{T}}>6,400$. This asymptotic behavior makes sense because the area encapsulated by the flame brush is finite and for cases in which $\operatorname{Re}_{\mathrm{T}}>22,000$ the preheat zone is seen to fill the entire central region of the flame (see Figures 9G, 9H, 10B, and 10D). Furthermore, comparing the lower and upper zones results presented in Figure 17 suggests that the average preheat zone thickness increases with height above burner.

An increase in preheat zone thickness with height above burner can be associated with the fact that the flame brush typically widens downstream of the HPB's exit, which is a consequence of its diverging nozzle. Additionally, this trend could potentially be attributed to elevated turbulence levels at moderate heights above the burner, which were observed in jet burners ${ }^{17,48}$. However, in order to validate this hypothesis, characteristics of the Hi-Pilot flow field must be assessed at regions downstream of its exit.

Another striking feature displayed in Figure 17 is that cases $1 \mathrm{c}-4 \mathrm{c}$ have much thicker preheat zones than the other cases. This is quite surprising, since CHEMKIN analysis of these rich $(\phi=1.05)$ flames give a much thinner preheat zone thickness than the other, lean $(\phi=0.75)$ flames. However, the fact that the preheat zone thicknesses in cases $1 c-4 c$ are so much greater than the other cases is likely a result of the larger FOV used to study these flames. That is, since the preheat zones tend to fill the central region of the flame brush, imaging a larger portion of the flame brush should yield thicker preheat zone measurements. 
The solid, black horizontal line in Figure 17 (which represents $2 * \delta_{\mathrm{PH}, \mathrm{L}}$ ) marks the boundary between "thin" and "thickened" preheat zones. The inequality defining this region is as follows:

$$
4>\frac{\delta_{\mathrm{PH}, \mathrm{T}}}{\delta_{\mathrm{PH}, \mathrm{L}}}>2
$$

Thus preheat zones that are more than two but less than 4 times as thick as those measured in a laminar flame are identified as being "thickened." The reason for setting this boundary at twice the measured laminar thickness is because, as Zhao et al. ${ }^{17}$ mention, three-dimensional effects and severe flame wrinkling could cause layers to appear up to twice as thick as they would in a laminar flame. The boundary between "thickened" and "primarily distributed" preheat layers is marked by the red horizontal line in Figure 17, which represents four times the measured laminar value. This boundary is defined by the inequality:

$$
\frac{\delta_{\mathrm{PH}, \mathrm{T}}}{\delta_{\mathrm{PH}, \mathrm{L}}}>4
$$

That is, the preheat zones associated with a particular case are deemed "primarily distributed" when the average preheat zone thickness exceeds four times the measured laminar value. This suggests that the lower zones of cases $2 a-4 a$ and $2 b-4 b$ and the upper zones of cases $2 a-4 a$ and $1 c-4 c$ all possess "primarily distributed" preheat zones. Only preheat layers within the lower zones of cases $1 \mathrm{a}$ and $1 \mathrm{~b}$ are identified as being thickened. The definition of this boundary is supported by the PLIF images displayed in Figures $12-16$. From Figure 12 it is apparent that the preheat zones of case $1 \mathrm{~b}$ are relatively thin. Conversely, case $2 \mathrm{~b}$ 's preheat zones are substantially more distributed and are even seen to cover a significant portion of the FOV shown in panels $(\mathrm{G})$ and $(\mathrm{H})$ of Figure 13. Thus, Eq. (12) appears to mark the border between "thickened" and "primarily distributed" preheat zones reasonably well.

As in Figure 17, the data displayed in Figure 18 is produced by averaging the reaction zone thicknesses over all images taken for each case.

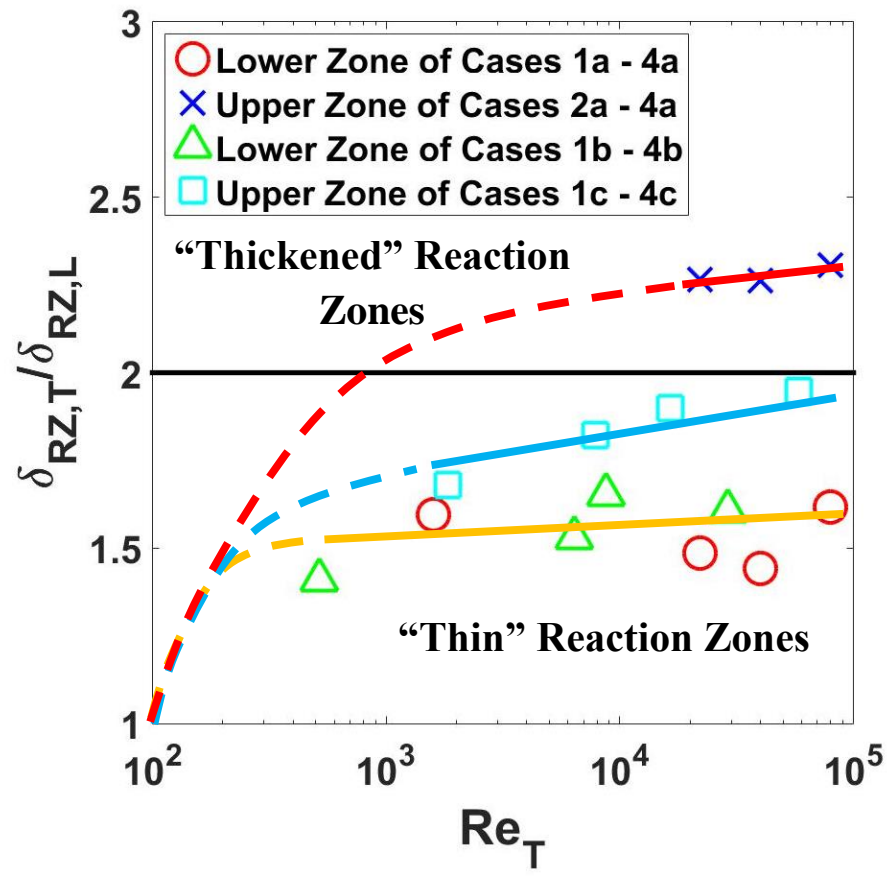

Figure 18. Average reaction zone thickness normalized by measured laminar reaction zone thickness $(0.39$ and 0.38 $\mathrm{mm}$ for the lean and rich flames, respectively) as a function of turbulence Reynolds number.

Unlike the average preheat zone thicknesses; Figure 18 implies that the average reaction zone thicknesses are relatively constant for a large range of turbulence intensities and integral length scales. This trend, or lack thereof, 
is consistent with the structural qualities of the reaction zones seen in Figures 12 - 16. Namely, while regions of distributed reactions were observed in cases with both high and low turbulence levels; they typically were accompanied by relatively thin reaction regions. Having both relatively thin and distributed reaction layers present in all of the cases is what leads to minor variation between the average reaction zone thicknesses.

Though the average reaction zone thicknesses vary only slightly within a particular zone, Figure 18 demonstrates that these values change considerably between zones. Specifically, the average reaction layer thicknesses in the upper zone of cases $2 \mathrm{a}-4 \mathrm{a}$ are up to 1.5 times thicker than those in the lower zone. This trend is supported by the PLIF images presented above. That is, while both possess a range of reaction zone structures, those in the upper zone of case 2a (see Figure 14) have a higher tendency of being thickened than those in the lower zone of case $2 b$ (see Figure 13). As in the case of the preheat zone thickness, this could be a result of increased turbulence levels at moderate heights above the burner. Yet, as mentioned above, properties of the flow field at regions downstream of the HPB's exit are necessary to justify this explanation. Such properties were unavailable for the current study.

Figure 18 clearly shows that the reaction layers in the upper zone of cases $1 \mathrm{c}-4 \mathrm{c}$ are thinner than those in the upper zone of cases $2 a-4 a$. This is consistent with the fact that both measurements and CHEMKIN simulations yield thinner laminar reaction layers for the near-stoichiometric flames. Yet, another reason why the average reaction layers in the upper zone of cases $2 c-4 c$ are thinner than in the upper zone of cases $2 a-4 a$ could be a result of the different pilot flames used. Unlike the large-pilot-flame used in cases $1 \mathrm{c}-4 \mathrm{c}$, the smaller-pilot-flame employed in cases $2 \mathrm{a}-4 \mathrm{a}$ did not always shield the flame from room-air entrainment (see Figures 15F, 14G, and $14 \mathrm{H})$. Images presented by Zhou et al. ${ }^{18}$ suggest that such entrainment is sometimes accompanied by distributed reaction layers. Hence, it is possible that in the absence of sufficient shielding, reaction layers could become thicker. However, further investigations at the same $\phi$ are required to justify this hypothesis. Though, based on Figure 18, it appears that the pilot has only a minor effect on the reaction layer thicknesses if any at all.

Similar to Figure 17, the solid black line in Figure 18 marks the boundary between regimes of "thin" and "thickened" reaction zones. Here, the black line is defined by the inequality:

$$
\frac{\delta_{\mathrm{RZ}, \mathrm{T}}}{\delta_{\mathrm{RZ}, \mathrm{L}}}>2
$$

That is, the reaction layers within in a particular zone of a specific case are designated as being "thickened" when that case's average reaction zone thickness exceeds twice the measured laminar value. From Figure 18, it is apparent that only the upper zone of cases $2 \mathrm{a}-4 \mathrm{a}$ possess thickened reaction layers; the rest have relatively thin, laminar-like reaction layers. This result is consistent with the appearance of the reaction layers exhibited in Figures 12 - 16; yet, it is quite intriguing. That is, the results demonstrate that reaction layers remain relatively thin even when the flames are subjected to extreme turbulence and the stabilizing pilot-flame is dramatically altered. Furthermore, though several of the cases are classified into the "distributed reaction" regime (see Figure 1), none of them display significantly broadened reaction layers. A discussion comparing the observed flame structures to those predicted by the regime diagram in Figure 1 is provided in the following section.

\section{Regime diagram inconsistencies}

In comparing the reaction zone structures observed here to those forecasted by the regime diagram presented in Figure 1, some distinctions are apparent. For example, the flow characteristics of case 4a place it within the "distributed reaction" regime, where reaction layers are theorized as being homogeneously spread throughout the entire domain of the turbulent flame brush ${ }^{49}$. However, the average reaction layers in the lower zone of this case are generally "thin" (i.e. they are less than twice the measured laminar reaction zone thickness). Furthermore, though the reaction layers in the upper zone of case $4 \mathrm{a}$ are (on average) "thickened," a significant fraction of them are still rather thin. Similarly, Cases 3a, 3b, and 4c all lie within or very near the "distributed reaction" regime; yet, none of them display a significant amount of reaction zone broadening. Additionally, though the reaction layers in the least turbulent case (case 1b) should theoretically be thin, pockets of thickened reactions do appear from time to time. Based on these findings it appears that classical flame structure descriptions posited by a case's position on the regime diagram fail to capture the features observed in actual flames. 
In addition to the discrepancies noted above, previous investigations ${ }^{48,50-52}$ have also noticed inconsistent correlations between observed flame structures and those predicted by a case's location on the regime diagram. For instance, though the least turbulent case of Dunn et al. ${ }^{48}$ was classified into the "distributed reaction" regime, temperature images of this case identified its reaction layers as being relatively thin. On the other hand, the most turbulent case investigated by Allison et al. ${ }^{52}$, which was also categorized into the "distributed reaction" regime, possessed thinner thermal layers than flames at lower turbulence levels.

Dunn et al. ${ }^{48}$ do offer a tentative explanation as to why their seemingly thin flame is classified into the "distributed reaction" regime. They point out that the regime diagram in Figure 1 assumes that turbulence-flame interactions only occur in the direction normal to the flame front and in flow fields that are homogeneous and only moderately turbulent. Yet, the flow field generated by their burner, as well as the one utilized in this study, is severely turbulent (e.g. u' $/ \mathrm{S}_{\mathrm{L}}>180$ ) and is most likely inhomogeneous. Other possible explanations for discrepancies between observed flame structures and the features projected by the regime diagram are as follows:

1. Classical theory posits that reaction zones become distributed or shredded when enough energy can be stored within turbulent flow structures that are able to penetrate the reaction zone of a laminar flame ${ }^{20}$. However, as shown above, the preheat zone becomes distributed for $\operatorname{Re}_{\mathrm{T}}>6,400$. Therefore, prior to reaching the reaction zone, turbulent structures first pass through the preheat zone, which consists of a relative large region of elevated temperatures. These elevated temperatures cause the local kinematic viscosity to increases, which enhances dissipation and thus draws energy away from the smallest turbulent structures. Hence, though turbulent structures of sufficient size and energy may exist at the burner's exit, it is possible that they are attenuated by the thick preheat layers before they reach the reaction zone. In this way, the broadening of preheat layers can be thought of as a defense mechanism that protects the reaction layers from the destructive turbulent flow field.

2. Turbulence intensities produced by the HPB are generally varied by changing the overall mass flow rate of the reactants. This implies that the most turbulent cases also possess the greatest flow velocities. Such high velocities likely reduce the interaction time between turbulent flow structures and the flame front. Without a sufficiently long residence time, it is possible for even the most violent of turbulent structures to pass over the flame front without significantly broadening or extinguishing it.

However, further investigations involving the simultaneous acquisition of both flow field and flame structure data are required to validate these premises. Such investigations are planned for the future. Nevertheless, the current investigation strongly suggests that the regime diagram requires alterations in order to accurately describe structural features of real turbulent flames. A starting point for such alterations are provided in section III.E below, where the cases presented in this document are categorized into their appropriate regimes of combustion.

\section{E. Regimes associated with the measurements to date}

As mentioned above, the data presented here as well as in other studies ${ }^{48,52-54}$, suggest that modifications should be made to the regime diagram. The present data set is too limited to provide a comprehensive re-mapping of the regime diagram; however, the cases studied here have been associated with a particular regime based on their structural features. Specifically, a case is classified as having "thickened" reaction layers if its mean reaction layer thickness is twice that of the measured laminar value. Additionally, if a case is found to have average preheat zone thicknesses that are greater than two but less than four times the measured laminar value they are recognized as having "thickened" preheat zones. On the other hand, if the average preheat zone thickness exceeds four times the measured laminar value that case is identified as having "primarily distributed" preheat zones.

The categorization of each case into its appropriate regime was based on the aforementioned definitions and the data shown in the figures above. A summary of this categorization is provided in Table 2 below. 


\begin{tabular}{|c|c|c|c|}
\hline Case & Interrogation region & Preheat zone & Reaction zone \\
\hline $1 \mathrm{a}$ & lower zone & "thickened" preheat zone & "thin" reaction layers \\
\hline $2 \mathrm{a}$ & $\begin{array}{l}\text { lower zone } \\
\text { upper zone }\end{array}$ & $\begin{array}{l}\text { "primarily distributed" preheat zone } \\
\text { "primarily distributed" preheat zone }\end{array}$ & $\begin{array}{l}\text { "thin" reaction layers } \\
\text { "thickened" reaction layers }\end{array}$ \\
\hline $3 a$ & $\begin{array}{l}\text { lower zone } \\
\text { upper zone }\end{array}$ & $\begin{array}{l}\text { "primarily distributed" preheat zone } \\
\text { "primarily distributed" preheat zone }\end{array}$ & $\begin{array}{l}\text { "thin" reaction layers } \\
\text { "thickened" reaction layers }\end{array}$ \\
\hline $4 a$ & $\begin{array}{l}\text { lower zone } \\
\text { upper zone }\end{array}$ & $\begin{array}{l}\text { "primarily distributed" preheat zone } \\
\text { "primarily distributed" preheat zone }\end{array}$ & $\begin{array}{l}\text { "thin" reaction layers } \\
\text { "thickened" reaction layers }\end{array}$ \\
\hline $1 b$ & lower zone & "thickened" preheat zone & "thin" reaction layers \\
\hline $2 b$ & lower zone & "primarily distributed" preheat zone & "thin" reaction layers \\
\hline $3 b$ & lower zone & "primarily distributed" preheat zone & "thin" reaction layers \\
\hline $4 \mathrm{~b}$ & lower zone & "primarily distributed" preheat zone & "thin" reaction layers \\
\hline $1 \mathrm{c}$ & upper zone & "primarily distributed" preheat zone & "thin" reaction layers \\
\hline $2 \mathrm{c}$ & upper zone & "primarily distributed" preheat zone & "thin" reaction layers \\
\hline $3 \mathrm{c}$ & upper zone & "primarily distributed" preheat zone & "thin" reaction layers \\
\hline $4 \mathrm{c}$ & upper zone & "primarily distributed" preheat zone & "thin" reaction layers \\
\hline
\end{tabular}

Table 2. Classification of the four cases studied in this paper.

\section{Conclusions}

1. Twelve different non-reacting flow fields issuing from the Michigan Hi-Pilot Burner (HPB) were characterized using laser Doppler Velocimetry (LDV). The turbulence Reynolds number of these four cases spanned from 520 to 80,000 , the turbulence intensity (i.e. $\mathrm{u}^{\prime} / \mathrm{S}_{\mathrm{L}}$ ) ranged from 5 to 184 , and the integral length scale varied between $6 \mathrm{~mm}$ and $29 \mathrm{~mm}$. Eight of the twelve cases were classified into a regime of extreme turbulence since their $\mathrm{u}^{\prime} / \mathrm{S}_{\mathrm{L}}$ values exceeded 25. Additionally, two of the cases fall within the "distributed reaction" regime because their $\mathrm{Ka}_{\mathrm{T}}$ values exceed $100^{20}$.

2. Preheat zone thicknesses (based on $\mathrm{CH}_{2} \mathrm{O}$ PLIF signals) were found to exceed 14 times the measured laminar value ( 0.42 and $0.39 \mathrm{~mm}$ for lean and rich flames, respectively). Ten of the twelve cases considered possessed average preheat zone thicknesses above four times the measured laminar thickness, hence these cases were identified as having "primarily distributed" preheat zones. The remaining two cases (i.e. the least turbulent cases) were found to have "thickened" preheat zones, since their average preheat zone thicknesses exceeded two but not four times the measured laminar value.

3. As the turbulence Reynolds number increases beyond 6,400, preheat zone thickness exhibit an asymptotic behavior. This is believed to stem from the fact that the area encapsulated by the flame brush is finite and that for $\operatorname{Re}_{\mathrm{T}}>22,000$ the preheat zone fills the entire central region of the flame. Therefore, the preheat zone cannot grow any larger for this geometry.

4. Reaction zones were identified by taking the pixel-by-pixel product of $\mathrm{OH}$ and $\mathrm{CH}_{2} \mathrm{O}$ PLIF images. For a particular interrogation region, no significant variation in average reaction zone thicknesses was observed. This is quite surprising because the flames investigated here were subjected to a wide range of turbulence levels and the stabilizing pilot-flame was drastically changed between some of the cases. 
5. The reaction layers were deemed "thin" in all of the cases except in the upper zone of cases $2 a-4 a$, which were found to possess "thickened" reaction layers. A case was identified as having "thin" ("thickened") reaction layers if the average reaction layer thickness in that case was less (more) than twice those measured in a laminar flame ( 0.39 and $0.38 \mathrm{~mm}$ for lean and rich flames, respectively).

6. In some cases the observed reaction zone structures deviated substantially from those predicted by the Borghi Diagram. In particular, cases classified into the "distributed regime" exhibited relatively thin reaction zones. Thus, it is likely that the regime diagram will have to be altered if it is to accurately describe structural features of real turbulent flames.

7. The current data set is too limited to provide a comprehensive re-mapping of the regime diagram. However, the cases considered in this study were classified into appropriate regimes of combustion.

\section{Acknowledgements}

Support for this research was provided by AFOSR Grant FA9550-12-1- 0101 that was monitored by Dr. Chiping Li.

\section{References}

${ }^{1}$ I.G. Shepherd, R. K. Cheng, Combust. Flame 127 (2001) 2066-2075.

${ }^{2}$ A. Buschmann, F. Dinkelacker, T. Schafer, M. Schafer, J. Wolfrum, J.. Proc Combust. Inst. 26 (1996) 437-445.

${ }^{3}$ A. Soika, F. Dinkelacker, A. Leipertz, Proc. Combust. Inst . 27 (1998) 785-792.

${ }^{4}$ Y.-C. Chen, R. W. Bilger, Combust. Flame 131(2002) 400-435.

5J. F. Driscoll, Prog. Energy \& Combust. Sci. 34 (2008) 91-134.

${ }^{6}$ A.M.Steinberg, J.F. Driscoll, Combust. Flame 156 (2009) 2285-2306.

${ }^{7}$ A. M. Steinberg, J. F. Driscoll, Expts. in Fluids 47 (2009) 527-547.

${ }^{8}$ J. B. Bell, M.S. Day, J. F. Grcar, M.J. Lijewski, J. F. Driscoll, S. Filatyev, Proc. Combust. Inst. 31 (2007) 12991307.

${ }^{9}$ H. Kobayashi, T. Kawahata, K. Seyama, T. Fujimari, J.S. Kim, Proc. Combust. Inst. 29 (2002) 1793-1800.

${ }^{10}$ R. Sankaran, E.R. Hawkes, J.H. Chen, JH., Proc, Combust, Inst, 31(2006)1291-1298.

${ }^{11}$ F.T.C. Yuen, O. Gulder, Proc. Combust. Inst. 34 (2013) 1393-1400.

${ }^{12}$ Mansour, M.S. Chen, Y.-C., Peters, N., Proc. Combust. Inst. 24 (1992) 461-468.

${ }^{13}$ Chen, Y.-C., Peters, N., Schneemann, G.A., Wruck, N., Renz, U., and Mansour, M.S. Combust. Flame 107 (1996) 223-244.

${ }^{14}$ Chen, Y.-C., Mansour, M.S. Appl. Phys. B64 (1997) 599-609.

${ }^{15}$ M.J. Dunn, A. R. Masri, R. W. Bilger, R.S. Barlow, G.S. Wang, Proc. Combust. Inst. 32 (2009) 1779-1786.

${ }^{16}$ M.J. Dunn, A. R. Masri, R. W. Bilger, R S. Barlow, Flow Turbulence Combust. 85 (2010) 621-648.

${ }^{17}$ B. Zhou, C. Brackmann, Z. Li, M. Alden, X. Bai, Combust. Inst. 35 (2015) $1409-1416$.

${ }^{18}$ B. Zhou, C. Brackmann, Q. Li, Z. Wang, P. Petersson, Z. Li, M. Alden, X. Bai, Combustion \& Flame, 162 (2015) 2937-2953.

${ }^{19}$ F. A. Williams, Combust. Flame 26 (1976) 269-276.

${ }^{20}$ N. Peters, Turbulent Combustion, Cambridge U. Press, Cambridge UK, 2000.

${ }^{21}$ A. J. Aspden, M. S. Day, J. B. Bell, J. Fluid Mech. 680 (2011) 287-320.

${ }^{22}$ R. Borghi, Prog. Energy Combust. Sci. 14 (4) (1988) 245-292.

${ }^{23}$ A. Marshall, P. Venkateswaran, D. Noble, J. Seitzman, T. Lieuwen, Expt. Fluids 51 (2011) 611-620.

${ }^{24}$ B. Videto, D. Santavicca, Combust. Sci. Technol. 76 (1991) 159-164.

${ }^{25}$ T. Hedman, K. Cho, A. Satija, L. Groven, R. Lucht, S. Son, Experimental observation of the flame structure of a bimodal ammonium perchlorate composite propellant using $5 \mathrm{kHz}$ PLIF, Combustion and Flame 159 (2012) 427-437

${ }^{26}$ M. Richter, R. Collin, J. Nygren, M. Alden, L. Hildingsson, B. Johansson, Studies of the Combustion Process with Simultaneous Formaldehyde and OH PLIF in a Direct-Injected HCCI Engine, JSME International Journal, Series B, Vol 48, No. 4, 2005.

${ }^{27}$ P.H. Paul, H.N. Najm, Proc. Combust. Inst. 27 (1998) 43-50. 
${ }^{28}$ H.N. Najm, O.M. Knio, P.H. Paul, P.S. Wyckoff, Combust. Sci. Tech. 140 (1998) 369-403.

${ }^{29}$ S. Böckle, J. Kazenwadel, T. Kunzelmann, D-I. Shin, C. Schulz, J. Wolfrum. Proc. Combust. Inst. 28 (2000) 279286

${ }^{30}$ M. Röder, T. Dreier, C. Schulz, Applied Physics B 107 (2012) 611-617.

${ }^{31}$ M. Röder, T. Dreier, C. Schulz, Proc. Combust. Inst. 34 (2013) 3549-3556.

${ }^{32}$ B.O. Ayoola, R. Balachandran, J.H. Frank, E. Mastorakos, C.F. Kaminski, Combust. Flame 144 (2006) 1-16.

${ }^{33}$ A. Fayoux, K. Zahringer, O. Gicquel,.C. Rolond, Proc. Combust. Inst. 30 (2005) 251-257.

${ }^{34}$ H.N. Najm, P.H. Paul, C.J. Mueller, P.S. Wyckoff, Combust. Flame 113 (1998) 312-332.

${ }^{35}$ C.M. Vagelopoulos, J.H. Frank, Proc. Combust. Inst. 30 (2004) 241-249.

${ }^{36}$ R. Balachandran, B.O. Ayoola, C.F. Kaminski, A.P. Dowling, E. Mastorakos, Combust. Flame 143 (2005) 37-55.

${ }^{37}$ J. Kariuki, A. Dowlut, R. Yuan, R. Balachandran, Proc. Combust. Inst. 35 (2015) 1443-1450.

${ }^{38}$ R. Yuan, J. Kariuki, A. Dowlut, R. Balachandran, E. Mastorakos. Proc. Combust. Inst. 35 (2015) 1649-1656.

${ }^{39}$ Wabel, T.M., Skiba, A.W., Temme, J.E., Driscoll, J.F., "Highly Turbulent Premixed Flame Structure - Integral Length Scale Effects", 9 $9^{\text {th }}$ U. S. National Combustion Meeting, Cincinnati, Ohio, May 2015.

${ }^{40}$ Temme, J.E., Wabel, T.M., Skiba, A.W., Driscoll, J.F., 52nd Annual Aerospace Sciences Meeting, (2015) Kissimmee FL. ISBN-13:9781624102561

${ }^{41}$ Z. Li, B. Li, Z. Sun, X. Bai, M. Alden, Combustion and Flame 157 (2010) 1087-1096.

${ }^{42}$ Sumengen, B., "A Matlab toolbox implementing Level Set Methods," Vision Research Lab at UC Santa Barbara, California, October 2005. [http://barissumengen.com/level_set_methods/. Accessed 3/15/14.].

${ }^{43}$ Osher, S., Fedkiw, R., Level Set Methods and Dynamic Implicit Surfaces, Springer, New York, 2003.

${ }^{44}$ Mayo, W.T. Jr., A discussion of limitations and extensions of power spectrum estimation with burst-counter LDV systems. International workshop on laser velocimetry, West Lafayette, Indiana, Purdue University, pp 90101, 1974.

${ }^{45}$ Tummers, M.J., Passchier, D.M. Spectral estimation using a variable window and the slotting technique with local normalization. Meas. Sci. Technol. 7:1541-1546, 1996.

${ }^{46}$ Wu, H., Patterson, G.K, Chemical Engineering Science, Vol. 44, No. 10, pp. 2207-2221, 1989.

${ }^{47}$ Kresta, S., Wood, P., Chemical Engineering Science, Vol. 48, No. 10, pp. 1761-1774, 1993.

${ }^{48}$ M.J. Dunn, A. R. Masri, R. W. Bilger, Combust. Flame 151 (2007) 46-60.

${ }^{49}$ Williams, F. A. 1985a Combustion Theory. Addison-Wesley.

${ }^{50}$ Chen, Y.-C. and Bilger, R. W., "Simultaneous 2-D Imaging Measurements of Reaction Progress Variable and OH

Radical Concentration in Turbulent Premixed Flames: Instantaneous Flame-Front Structure," Combust. Sci. and Technol. 167, 2001, p.187-222.

${ }^{51}$ Y.-C. Chen, R. W. Bilger, Combust. Flame 138 (2004) 155-174.

${ }^{52}$ Allison, P.M., Shen, H., McManus, T.A., Sutton, J.A., 52nd Annual Aerospace Sciences Meeting, (2015) Kissimmee FL.

${ }^{53}$ Monin, A.S., Yaglom, A.M. (1975) Statistical Fluid Mechanics: Mechanics of Turbulence MIT Press, Cambridge, MA. 